\title{
RESEARCH
}

Open Access

\section{Autism spectrum disorders, endocrine disrupting compounds, and heavy metals in amniotic fluid: a case-control study}

\author{
Manhai Long ${ }^{1 *}$ (D), Mandana Ghisari', Lisbeth Kjeldsen ${ }^{1}$, Maria Wielsøe ${ }^{1}$, Bent Nørgaard-Pedersen²,
} Erik Lykke Mortensen ${ }^{3}$, Morsi W. Abdallah ${ }^{4}$ and Eva C. Bonefeld-Jørgensen ${ }^{1,5}$

\begin{abstract}
Background: Evidence has indicated that some non-inherited factors such as exposure to environmental pollutants are associated with neurodevelopment disorders like autism spectrum disorder (ASD). Studies report that endocrine disrupting compounds (EDCs), including polychlorinated biphenyls, organochlorine pesticides, perfluoroalkyl substances (PFAS), and some metals, have adverse effects on the fetal neurodevelopment. The aim of this study was to measure the amniotic fluid (AF) levels of EDCs and metals as well as the receptor transactivities induced by AF and investigate the possible link between prenatal exposure to EDCs and heavy metals and ASD risk.
\end{abstract}

Methods: In this case-control study, we included AF samples of 75 ASD cases and 135 frequency-matched controls and measured the levels of the endogenous sex hormones, PFAS, and elements including heavy metals. The combined effect of endogenous hormones and EDCs on the receptor of estrogen (ER), androgen (AR), aryl hydrocarbon (AhR), and thyroid hormone-like activity were also determined and expressed as receptor ligand equivalents. We assessed the associations of AF levels of chemicals, sex hormones, and receptor activities with ASD risk using unconditional logistical regression analyses. To control for multiple comparisons, the false discovery rate (FDR) was used and $q$ values less than 0.25 were designated as statistical significance.

Results: PFAS and metals were detectable in AF samples. The ASD cases had significantly lower AF levels of PFAS than controls, and the adjusted odds ratio (OR) was 0.410 (95\% Cl 0.174, 0.967; $p=0.042$; FDR qvalue $=0.437$ ) for perfluorooctane sulfonate (PFOS). The principal component, including PFAS congeners, copper, iron, and estrogenic activity, was significantly inversely associated with $A S D$ risk (adjusted $O R=0.100 ; 95 \% \mathrm{Cl} 0.016,0.630 ; p=0.014 ;$ FDR $q_{\text {value }}=0.098$.

Testosterone level in AF weakly associated with ASD risk (adjusted $\mathrm{OR}=1.002 ; 95 \% \mathrm{Cl} 1.000,1.004 ; p=0.05$ ). However, after multiple comparison correction, the association was not significant (FDR qualue $=0.437$ ). No significant associations between AF-induced receptor transactivities and ASD risk were observed. The adjusted OR was $2.176(95 \% \mathrm{Cl} 0.115,41.153)$ for the ratio of the combined androgenic activity to combined estrogenic activity.

Conclusions: The presence of PFAS and heavy metals in AF indicates that they can cross the placenta. The inverse association between levels of PFAS congeners in AF and ASD risk might relate to the weak estrogenic activities and anti-androgenic activities of PFAS.

The observed tendency of positive association between the ratio of combined androgenic effect to the combined estrogenic effect and ASD risk needs further studies to explore whether EDCs together with endogenous hormones play a role in the development of ASD.

Keywords: Autism, Endocrine disrupting compounds, Receptor activity, Amniotic fluid

\footnotetext{
*Correspondence: ml@ph.au.dk

${ }^{1}$ Centre for Arctic Health \& Molecular Epidemiology, Department of Public

Health, Aarhus University, Aarhus, Denmark

Full list of author information is available at the end of the article
}

(c) The Author(s). 2019 Open Access This article is distributed under the terms of the Creative Commons Attribution 4.0 International License (http://creativecommons.org/licenses/by/4.0/), which permits unrestricted use, distribution, and reproduction in any medium, provided you give appropriate credit to the original author(s) and the source, provide a link to the Creative Commons license, and indicate if changes were made. The Creative Commons Public Domain Dedication waiver (http://creativecommons.org/publicdomain/zero/1.0/) applies to the data made available in this article, unless otherwise stated. 


\section{Background}

Autism spectrum disorder (ASD) is a group of heterogeneous neurodevelopmental disorders characterized by qualitative impairments in social interaction, communication, and repetitive or stereotyped behavior [1]. Epidemiological studies indicate an increasing worldwide prevalence of ASD during the last decades [2, 3]. In Denmark, prevalence of ASD has increased between 1972 and 2007 and a recent estimate was approximately $0.74 \%$ [4].

The etiology of ASD is not fully clarified. Despite the evidence of a genetic component [5], genetic factors cannot fully explain ASD, and single gene and chromosomal defects only account for a minority of ASD cases (10$20 \%)[6,7]$. The accumulating evidence shows that some non-inherited factors such as exposure to environmental pollutants and neurotoxins are associated with ASD risk [8-11]. Moreover, studies suggest that the endocrine system plays a role in the etiology of ASD [12]. Autistic traits were increased following prenatal exposure to abnormally high levels of testosterone caused by congenital adrenal hyperplasia [13]. ASD was linked with elevated fetal testosterone levels in amniotic fluid during routine amniocentesis [14]. A study in 192 twins reported that environmental factors accounted for $55 \%$ of the risk of developing ASD compared with genetic factors accounting for $37 \%$ [15]. One review reported that $89 \%$ of the included publications implicated an association between environmental toxicants and ASD [16].

Children are vulnerable to the neurotoxic effects of chemicals, especially during the prenatal period, when there is an immature blood-brain barrier and neuronal growth, migration, and myelination processes that occur on a specific and rapid schedule [17, 18]. Moreover, some toxic substances can pass through the placental barrier and easily access the developing brain and interfere with these important processes, possibly leading to adverse outcomes [17]. Some environmental pollutants can interfere with the endocrine system acting as endocrine disrupting compounds (EDCs), including persistent organic pollutants (POPs) such as polychlorinated biphenyls (PCBs), organochlorine pesticides (OCPs), polybrominated diphenyl ethers (PBDEs), dioxins [19-22], perfluoroalkyl substances (PFAS) [23, 24], and non-persistent compounds like bisphenol A [25-27].

EDCs may alter endogenous axes and interfere with steroid-dependent neurodevelopment and modify the ASD risk $[28,29]$. A variety of EDCs in blood and urine samples of pregnant women were reported to be related to children's autistic behavior [12]. Animal studies reported that PFAS had adverse effects on neurodevelopment [30, 31]. A Korean study showed that mothers of children with ASD had higher exposure to PBDEs, PCBs, bisphenol A, and dioxins through canned food, plastics, waste incinerators, old electronics, microwavable food, and textiles compared to mothers with typically developing children [32]. Studies have linked autistic behavior with prenatal exposure to the organophosphate insecticide chlorpyrifos [33] and phthalates [34]. In addition, a study reported that gestational exposure to the OCPs, dicofol and endosulfan, was associated with an increased risk of ASD [9]. Parental occupational exposure to chemicals such as solvent xylene was reported to be associated with ASD [35]. Some elements and heavy metals, such as iron $(\mathrm{Fe})$, copper $(\mathrm{Cu})$, zinc $(\mathrm{Zn})$, selenium $(\mathrm{Se})$, iodine (I), arsenic (As), mercury $(\mathrm{Hg})$, cadmium $(\mathrm{Cd})$, lead $(\mathrm{Pb})$, and manganese $(\mathrm{Mn})$, might impact on the development of the nervous system [29, 36-41]. Perinatal exposure to air pollutants, including $\mathrm{Hg}, \mathrm{Pb}$, and $\mathrm{Mn}$, was linked to an increased risk of ASD with stronger associations for boys [42].

Humans are exposed to dozens of potential EDCs across the lifespan. The fetus and infant have relatively greater exposure to some EDCs and are more vulnerable than adults. Multiple EDCs may have a combined effect, and the health-related consequences of EDC mixtures are thus of concern. An approach to assess the combined EDC effects of complex EDC mixtures is to measure the overall impact of all EDCs present in a sample on the hormone receptor-mediated transactivation such as measurement of estrogen receptor (ER) transactivity, androgen receptor (AR) transactvity, thyroid hormone (TH) function, and aryl hydrocarbon receptor (AhR) transactivity in the biological samples using ex vivo mammalian cell culture systems [43, 44].

The matrices for prenatal exposure biomarkers are often maternal blood and umbilical cord blood, but correlations with measures in fetal compartments can be low. In practice, umbilical cord blood is obtainable only at birth, but the expected vulnerable time window for many health outcomes is often earlier in the pregnancy (e.g., during organogenesis). Amniotic fluid (AF) offers another possible fetal matrix, but samples are most often only available from amniocentesis indicated by advanced maternal age or by prenatal diagnostics of chromosomal abnormalities and severe malformations. It is a major advantage, however, that amniocentesis is usually performed within the second trimester (gestational weeks 13 to 28), which may be closer to the expected vulnerable period for many adverse outcomes. It is suggested that contaminant concentrations in AF during the first half of pregnancy (before 20 weeks of gestation) can be a suitable proxy measure of intra-fetal contaminant exposure, because AF is derived mainly from fetal blood and fluids during this period [45]. Studies have shown that the risk of autism tends to be higher upon exposures within the first half of pregnancy [46]. Although contaminants in maternal blood or umbilical cord blood are 
used as a proxy for fetal exposure, little is known about the actual exposure level of the fetus.

The purpose of this study was using AF to (1) measure EDCs and elements including heavy metals, (2) determine the receptor transactivities induced by EDCs, and (3) perform a case-control study to investigate the hypothesis that in utero exposure to EDCs and heavy metals is associated with an increased risk for ASD. In addition, principle component analysis was used to identify the potential underlying components of substances in AF to explore the effect of substance mixture on ASD risk.

\section{Methods}

\section{Study population and sample selection}

Figure 1 presents the case and control selection process. Study subjects were initially selected from a population of singleton births between 1982 and 1999 with AF samples available as part of the Historic Birth Cohort (HBC) stored at the Statens Serum Institute (SSI) in Copenhagen, Denmark [47]. The HBC is based on a collection of antenatal biological samples obtained during screening/diagnostic procedures performed mainly in three Danish regions. The collection of samples goes from the late 1970s until 2004 and includes more than 100,000 samples of AF, bloodspots, and maternal serum samples (Fig. 1) [14, 48]. The AF samples from the HBC were centrifuged after routine screening or diagnostic amniocentesis, and samples were kept frozen at $-20^{\circ} \mathrm{C}$ until further analyzed [49]. The Danish nation-wide health registers were employed to follow-up individuals in the HBC until 2009. All psychiatric diagnoses were identified utilizing the Danish Psychiatric Central Register (DPCR) which has high diagnosis validity of infantile autism diagnoses [50]. All singleton ASD cases born during 1982-1999 were identified according to the International Classification of Diseases (ICD)-8 codes 299. $x x$ up to 1993 and ICD-10 codes DF84.xx since 1994. Furthermore, the Danish National Hospital Register (DNHR) primary diagnoses [51] were applied to complement diagnoses of congenital malformations and other psychiatric comorbidities. The birth record data of the study subjects were retrieved from the Danish

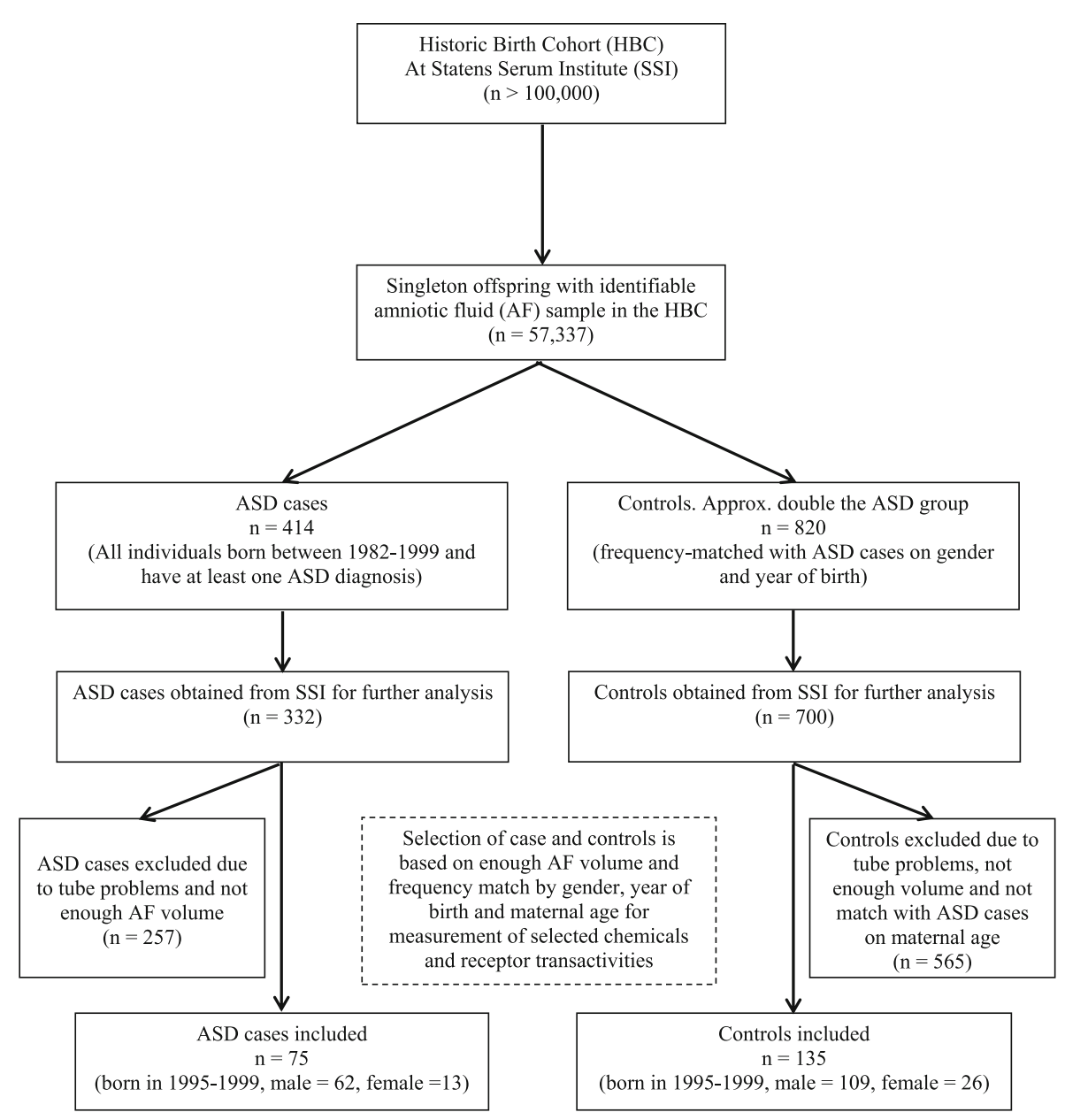

Fig. 1 Flow chart of autism disorders (ASD) and controls selection process 
medical birth registry [52]. The controls were non-ASD individuals randomly retrieved from the $\mathrm{HBC}$ and frequency-matched with cases on gender and year of birth [47].

The present study aims to examine whether EDCs in AF influence individuals diagnostics with ASD later in life using the case-control design. We first performed a pilot study on pooled AF to establish methods for the EDC-receptor function analyses and measurement of POPs such as PCBs, OCPs, and PFAS as well as elements including heavy metals. The pilot study showed that the levels of lipophilic POPs (PCBs, OCPs, dioxins, PBDEs) in AF samples were below the detection limits while PFAS, elements/metals, and AF-induced combined receptor transactivities could be detected in AF samples. Therefore, 1032 individual AF samples including 332 ASD cases and 700 controls were obtained from the SSI and stored at $-20^{\circ} \mathrm{C}$ in Centre for Arctic Health \& Molecular Epidemiology, Department of Public Health, Aarhus University, Denmark, for the determination of PFAS, elements, and the combined ex vivo receptor transactivities (ER, AR, AhR, and TH). Since many parameters had to be determined in each AF sample, the first selection of samples was based on available samples having adequate volume. AF samples of ASD cases and controls with adequate volume were thus selected and frequency-matched by gender and year of birth. Due to the possible influence of maternal age on ASD, the ASD cases and controls were further matched by maternal age with approximately 1:2 case-control match (Fig. 1).

Changes in concentrations of analytes over prolonged times are a known issue [53], and the way the samples were stored pre- and post-1993 was different. Baron-Cohen reported the evidence of evaporation and the concentrations of various analytes of pre-1993 samples were higher than those of post-1993 samples [14]. In addition, after 1993, the timing of amniocentesis in Denmark was standardized using ultrasound to mark gestational age and diagnostic information after 1993 became much more reliable by switching to ICD-10 [50, 54]. Therefore, the present study was restricted to individuals born between 1993 and 1999. However, several samples were stored in tubes with blue rubber caps containing cell toxic compounds affecting cell culture growth. Those samples were excluded from the present study. Finally, 75 ASD cases (62 boys, 13 girls) and 135 frequency-matched controls (109 boys, 26 girls) born during 1995-1999 with adequate AF volume were included in the study (Fig. 1).

\section{Perfluoroalkyl substances (PFAS) measurements}

The concentrations of PFAS in AF were measured at the Institute for Environmental Science, Aarhus University, Denmark. The extraction method was based on ion pairing as described previously [55]. Six perfluorosulfonated acids (PFSA) and eight perfluorocarboxylated acids (PFCA) were determined by liquid chromatography-tandem mass spectrometry (LC-MS-MS) with electrospray ionization (ESI) [56]. The measured PFSA were perfluorooctane sulfonate (PFOS), perfluoroheptane sulfonate (PFHpS), perfluorobutane sulfonate (PFBS), perfluorohexane sulfonate (PFHxS), perfluorodecane sulfonate (PFDS), and perfluorooctane sulfonamide (PFOSA). The sum of PFOS, PFHpS, PFBS, PFHxS, PFDS, and PFOSA was given as $\Sigma$ PFSA. The measured PFCA were perfluorooctanoic acid (PFOA), perfluorohexanoic acid (PFHxA), perfloroheptanoate (PFHpA), perfluorononanoic acid (PFNA), perfluorodecanoic acid (PFDA), perfluoroundecanoic acid (PFUnA), perfluorododecanoic acid (PFDoA), and perfluoro-n-pentanoic acid (PFPeA). The sum of PFOA, PFHxA, PFHpA, PFNA, PFDA, PFUnA, PFDoA, and PFPeA was given as $\Sigma$ PFCA. Half of the limit of quantification values were used for concentrations below the limit of quantification (Additional file 1).

\section{Measurement of elements and metals}

The concentrations of 59 elements and heavy metals in AF were determined using inductively coupled plasma mass spectrometry (ICP-MS) after dilution 20 times with $5 \%$ nitric acid at the Institute for Bioscience-Arctic Research Centre, Aarhus University, Denmark. The quality was ensured by participation in the Quality Assurance of Information in Marine Environmental monitoring (QUASIMEME) inter-laboratory comparison program [57]. The detection limits of measured elements were obtained as three times the standard deviation of blind (acid alone). Half of the detection limit values were used for concentrations below the detection limit (Additional file 2).

\section{Measurement of endogenous sex hormones}

The endogenous sex hormone levels in AF were determined by solid phase fluoroimmunoassays. The DELFIA ${ }^{\circ}$ Estradiol kit and Testosterone kit (PerkinElmer Life and Analytical Sciences, Wallac Oy, Turku, Finland) [58] were used to measure the levels of estrogen $17 \beta$-Estradiol (E2) and androgen testosterone, respectively, at the Centre of Arctic Health \& Molecular Epidemiology, Department of Public Health, Aarhus University, Denmark. The DELFIA kits offer a faster method for measuring estradiol and testosterone with adequate sensitivity compared to radioimmunoassays [59]. The detection limit was $13.62 \mathrm{pg} / \mathrm{mL}$ and $115.4 \mathrm{pg} /$ $\mathrm{mL}$ for $\mathrm{E} 2$ and testosterone, respectively. The intra-assay and inter-assay coefficient of variation was $10.0 \%$ and 9.7\% for E2 and $5.7 \%$ and $8.4 \%$ for testosterone, respectively. 


\section{Measurement of receptor transactivities induced by AF}

To evaluate the potential of the compounds/molecules in AF to interfere with the estrogen receptor (ER), androgen receptor (AR), and aryl hydrocarbon receptor (AhR) transactivation, the luciferase reporter gene transactivities (tact) of these receptors (ER-tact, AR-tact, and AhR-tact) were determined. For thyroid hormone (TH)-related action, the proliferative effect (TH-PE) of AF was determined using a TH-dependent GH3 cell proliferation assay (T-screen assay) at the Centre for Arctic Health \& Molecular Epidemiology, Department of Public Health, Aarhus University, Denmark. The established luciferase reporter gene bioassays [20, 27, 60] and the T-screen assay [21] have been described earlier in detail.

The AF-induced ER-tact was determined by direct exposure of the stably transfected MVLN cells to $6.25 \mu \mathrm{l}$ AF dissolved in $100 \mu \mathrm{l}$ of culture medium (CD-FCS DMEM). In parallel, an eight-point E2 series (3.1-300 pM) was included as a positive control and used for estradiol equivalent (ER-EEQ) calculation.

The AF-induced AR-tact was determined by direct exposure of transiently transfected $\mathrm{CHO}-\mathrm{K} 1$ cells to $5 \mu \mathrm{l}$ AF dissolved in $100 \mu \mathrm{l}$ of culture medium (DMEM/F12 $+10 \%$ CD-FCS). In parallel, an eight-point dihydrotestosterone (DHT) series (2-200 pM) was included as a positive control and used for calculation of the androgen equivalent (AR-AEQ).

The TH-disrupting potential of AF (TH-PE) was analyzed in the T-screen assay by exposing the GH3 cells to $14 \mu \mathrm{l}$ of AF in $200 \mu \mathrm{l}$ thyroid hormone-depleted CD-FCS DMEM. In parallel, an eight-point triiodothyronine (T3) series (10-10,000 pM) was included as a positive control and for calculation of the thyroid equivalent (T3-ThEQ).

We measured the AhR transactivity (AhR-tact) of AF by exposure of Hepa1.12cR cells to an AF extract. The AF extracts were prepared as follows: $500 \mu \mathrm{l}$ AF was extracted on a solid phase extraction (SPE) column (Discovery C18, Sigma-Aldrich), eluted with hexane and evaporated to near dryness. The SPE extract of AF was dissolved in $1 \mu \mathrm{l}$ DMSO, and $400 \mu \mathrm{l}$ of culture medium (alpha MEM) was added. The cells were exposed to $100 \mu \mathrm{l} /$ well of this solution of AF extract, and the AhR-tact was determined. As procedural blank, $500 \mu \mathrm{l}$ distilled water was extracted, processed, and analyzed in the same way as the AF samples. In parallel, a nine-point $\quad 2, \quad 3, \quad 7, \quad 8$-tetrachlorodibenzo- $p$-dioxin (TCDD, potent AhR ligand) series (2-5000 pM) was included as a positive control and used for calculation of the AhR-TCDD equivalent (AhR-TEQ).

\section{Calculation of receptor ligand equivalent (EQ)}

The combined effect on the hormone receptors induced by the endogenous hormones and EDCs present in AF was calculated as the corresponding receptor ligand equivalent (EQ). Table 1 shows an explanation of measured receptor transactivities induced by AF and calculation of EQ. Briefly, the receptor ligand EQ was calculated by interpolation of the measured transactivity value of ER-tact, AR-tact, and TH-PE on the corresponding ligand dose-response four-parameter sigmoidal Hill curve and expressed as ER-EEQ (pg E2/mL AF), AR-AEQ (pg DHT/mL AF), and T3-ThEQ (ng T3/mL $\mathrm{AF})$, respectively. The integrated xenoestrogenic effect induced by EDCs alone was estimated by subtracting concentration of endogenous E2 from ER-EEQ and expressed as EDC-EEQ (pg E2/mL AF). For those ER-EEQ values less than the levels of E2, half of E2 detect limit was given as their EDC-EEQ values. We did not measure the DHT level but the testosterone level. The literature reported that almost $10 \%$ of the testosterone is converted to DHT [61]. In our lab, we observed that the potential of testosterone activating AR is 10 times less than DHT; this is similar to a previous study [62]. Thus, we estimated the level of endogenous DHT to be $10 \%$ of measured testosterone and subsequently the EDC-induced xenoandrogenic effect was obtained by subtracting the estimated endogenous DHT level from AR-AEQ and expressed as EDC-AEQ (pg DHT/mL AF) (Table 1). For those AR-AEQ values lower than levels of DHT, $10 \%$ of half testosterone detect limit was given as their EDC-AEQ values. To explore whether the endogenous sex hormones and/or EDCs influence the balance between androgenic effect and estrogenic effect, the ratio of AR-AEQ to ER-EEQ (AR-AEQ/ER-EEQ) and ratio of EDC-AEQ to EDC-EEQ (EDC-AEQ/EDC-EEQ) were further calculated. AR-AEQ/ER-EEQ represents the proportion of total combined androgenic effect to the total combined estrogenic effect. EDC-AEQ/EDC-EEQ reflects the proportion of EDC-induced androgenic effect to EDC-induced estrogenic effect.

The TCDD equivalent (AhR-TEQ) values of the AF extracts and procedural blank were estimated by interpolation of their AhR-tact values on the TCDD dose-response three-parameter sigmoidal Hill curve. The final net AhRTEQ of AF (pg TCDD/mL AF) was obtained by subtracting the procedure blank TEQ value (Table 1).

\section{Statistical analysis}

Only the chemicals of interest and receptor transactivities that were detectable in at least $10 \%$ of the AF samples were included in the statistical analyses. Because not all biomarkers were detected in all AF samples and data were skewed, we compared the differences of exposure biomarkers between the ASD cases and controls using the non-parametric Mann-Whitney test.

We used Spearman's correlation analysis to analyze the correlation of PFAS, elements, receptor transactivities, and potential confounders. 
Table 1 Explanation of measured receptor transactivities induced by amniotic fluid (AF) and receptor ligand equivalent calculation

\begin{tabular}{|c|c|c|}
\hline Abbreviations & Explanation & Example of calculation \\
\hline ER-tact & Luciferase reporter gene transactivity of estrogen receptor (ER) & \\
\hline ER-EEQ & $\begin{array}{l}\text { The combined effect on ER induced by the combination of endogenous estrogen and } \\
\text { xeno-estrogens (EDCs) given as estradiol equivalent }\end{array}$ & $\begin{array}{l}\text { - ER-tact of AF: } 2.51 \\
\text { - Interpolation of ER-tact onto E2 dose- } \\
\text { response curve } \\
\text { - ER-EEQ }=247.60 \mathrm{pg} \mathrm{E2} / \mathrm{ml} \mathrm{AF}\end{array}$ \\
\hline EDC-EEQ & $\begin{array}{l}\text { The integrated estrogenic effect induced by xeno-estrogens (EDCs) alone given as estra- } \\
\text { diol equivalent }\end{array}$ & $\begin{array}{l}\text { - Endogenous E2: } 230.23 \mathrm{pg} / \mathrm{ml} \\
\text { - }(\mathrm{ER}-\mathrm{EEQ})-\mathrm{E} 2=247.60-230.32=17.28 \mathrm{E} 2 \\
\mathrm{pg} / \mathrm{ml} \mathrm{AF}\end{array}$ \\
\hline AR-tact & Luciferase reporter gene transactivity of androgen receptor (AR) & \\
\hline AR-AEQ & $\begin{array}{l}\text { The combined effect on AR induced by the combination of endogenous androgens and } \\
\text { xeno-androgens (EDCs) given as androgen equivalent }\end{array}$ & $\begin{array}{l}\text { - AR-tact of AF: } 3.30 \\
\text { - Interpolation of AR-tact onto DHT dose- } \\
\text { response curve } \\
\text { - AR-AEQ }=63.50 \mathrm{pg} \mathrm{DHT/ml} \mathrm{AF}\end{array}$ \\
\hline EDC-AEQ & $\begin{array}{l}\text { The integrated androgenic effect induced by xeno-androgens (EDCs) alone given as an- } \\
\text { drogen equivalent }\end{array}$ & $\begin{array}{l}\text { - Testosterone: } 470.12 \mathrm{pg} / \mathrm{ml} \text { AF } \\
\text { - DHT: estimated DHT }=10 \% \times 470.12= \\
47.01 \mathrm{pg} / \mathrm{ml} \text { AF } \\
\text { - }(\text { AR-AEQ) - DHT }=63.50-47.01=16.49 \mathrm{pg} \\
\text { DHT/ml AF }\end{array}$ \\
\hline $\begin{array}{l}\text { AR-AEQ/ER- } \\
\text { EEQ }\end{array}$ & $\begin{array}{l}\text { The proportion of total combined androgenic effect to the total combined estrogenic } \\
\text { effect }\end{array}$ & $\begin{array}{l}\cdot \text { AR-AEQ }=63.50 \mathrm{pg} \text { DHT } / \mathrm{ml} / \mathrm{AF} \\
\cdot \mathrm{ER}-\mathrm{EEQ}=247.60 \mathrm{pg} \mathrm{E} 2 / \mathrm{ml} \mathrm{AF} \\
\cdot \text { AR-AEQ/ER-EEQ }=63.50 / 247.60=0.256\end{array}$ \\
\hline $\begin{array}{l}\text { EDC-AEQ/ } \\
\text { EDC-EEQ }\end{array}$ & The proportion of EDC-induced androgenic effect to EDC-induced estrogenic effect & $\begin{array}{l}\cdot \mathrm{EDC}-\mathrm{AEQ}=16.49 \mathrm{DHT} / \mathrm{mlAF} \\
\cdot \mathrm{EDC}-\mathrm{EEQ}=17.28 \mathrm{E} 2 / \mathrm{mlAF} \\
\cdot \mathrm{EDC}-\mathrm{AEQ} / \mathrm{EDC}-\mathrm{EEQ}=16.49 / 17.28=0.954\end{array}$ \\
\hline $\mathrm{TH}-\mathrm{PE}$ & Thyroid hormone-related proliferative effect & \\
\hline T3-ThEQ & $\begin{array}{l}\text { The combined proliferation effect (PE) of endogenous thyroid hormone and xeno- } \\
\text { thyroid hormone-like compounds (EDCs) given as thyroid equivalent }\end{array}$ & $\begin{array}{l}\cdot \text { TH-PE of AF: } 4.56 \\
\text { • Interpolation of TH-PE onto T3 dose- } \\
\text { response curve } \\
\cdot \text { - T3-ThEQ }=3.53 \mathrm{ng} \mathrm{T3/ml} \mathrm{AF}\end{array}$ \\
\hline AhR-tact & Luciferase reporter gene transactivity of aryl hydrocarbon receptor (AhR) & \\
\hline AhR-TEQ & The combined effect on AhR of dioxin-like compounds given as TCDD equivalent & $\begin{array}{l}\text { - AhR-tact of AF extraction: } 5.67 \\
\text { - AhR-tact of blank: } 4.75 \\
\text { - Interpolation of AhR-tact onto TCDD } \\
\text { dose-response curve = AhR-TEQ } \\
\text { - AhR-TEQ of AF extraction = } 1.46 \mathrm{pg} \mathrm{TCDD/} \\
\mathrm{ml} \text { - } \\
\text { - AhR-TEQ of blank }=1.22 \mathrm{pg} \text { TCDD } / \mathrm{ml} \\
\text { - } \text { Final AhR-TEQ }=1.46-1.22=0.24 \mathrm{pg} \\
\mathrm{TCDD} / \mathrm{ml} \text { AF }\end{array}$ \\
\hline
\end{tabular}

$A F$ amniotic fluid, $A E Q$ androgen equivalent, $A R$ androgen receptor, $A h R$ aryl hydrocarbon receptor, $D H T$ dihydrotestosterone, EDCs endocrine disrupting compounds, EEQ estradiol equivalent, $E R$ estrogen receptor, E2 $17 \beta$-Estradiol, $P E$ proliferation effect, TCDD 2, 3, 7, 8-tetrachlorodibenzo-p-dioxin, TEQ TCDD equivalent, $T 3$ triiodothyronine, ThEQ thyroid equivalent

To analyze the association of prenatal EDC exposure and ASD risk, unconditional logistical regression analysis was used to estimate the odds ratio (OR) and 95\% confidence interval $(95 \% \mathrm{CI})$. The levels of PFAS, elements, and receptor transactivities were included as continuous variables into the model with and without potential confounders.

The change in estimate principle [63] was used to identify the confounders using a cutoff of $5 \%$. Potential confounders available for this analysis included birth year and gender of child, maternal age at child birth, paternal age at child birth, birth weight, gestational age at birth, gestational week at sampling, Apgar score, and parity based on a priori consideration of the research design and ASD risk factors [64-66]. Given that ASD risk is also driven by genetic factors, we further adjusted for congenital malformation.

Twenty-nine individual exposure variables were detected in more than $10 \%$ of samples, and multiple comparisons were performed. We controlled for multiple comparisons using false discovery rate (FDR; $q_{\text {value }}$ ) correction as suggested by Benjamini-Hochberg [67, 68]. Since the present study is the first study to explore the associations of autism risk with chemicals and AF-induced receptor transactivity, a false discovery rate of 0.25 (FDR $q_{\text {value }}<0.25$ ) was used as a significant level for the multiple comparison correction [69]. 
ASD possesses gender difference with male preponderance [70], and ASD is associated with a higher rate of congenital malformation [71]. In addition, we suspected possible modification effect of gender. We therefore further performed the sensitivity analysis by stratifying on children's gender and excluding congenital malformation diagnoses.

\section{Principal component analysis}

The use of a large number of individual parameters would create a certain number of false positive results when performing multiple comparisons. Principal component analysis (PCA) is a powerful multivariate analytical tool and is applied to reduce a set of original variables and to extract a smaller number of principal components. Using PCA for data transformation is a common ad hoc tool to deal with multicollinearity in multiple regression models because the correlation between related compounds such as PFAS congeners exists and this multicollinearity biases the estimation of individual regression coefficients to cause misleading interpretation of the effects of individual predictor variables $[72,73]$. PCA reduces the false positives by reducing the number of variables [74]. Besides, people are exposed to the mixture of different substances simultaneously, it is important to assess the effect of actual effect of mixture and PCA might provide the possibility to address this issue. Therefore, we further used PCA to identify potential underlying components of levels of PFAS, metals, and receptor transactivities in AF. By PCA, the correlated variables are grouped together. The coefficients defining these linear combinations, termed as "factor loadings," are the correlations of each input variables with the component. The biomarkers which were detectable in more than $10 \%$ of all AF samples were input into the model to extract principal components (PCs). The number of PCs was extracted based on the eigenvalues $>1$ and Varimax rotation [75]. The Kaiser-Mayer-Olkin $(\mathrm{KMO})$ test $(>0.500)$ and Bartlett Test of Sphericity $(p<$ 0.001 ) were used for testing the suitability of analysis. All factors loading $>|0.3|$ were used to identify the variables comprising a PC.

The difference of identified PCs between cases and controls was analyzed by Mann-Whitney test. The association of identified PCs and ASD risk was also analyzed by logistic regression model with and without adjustment of potential confounders. FDR correction and sensitivity analysis were also performed for the identified principle components.

All statistical analyses were performed using SPSS version 24.0 (SPSS Inc. Chicago, IL, USA) conducted at the Centre of Arctic Health \& Molecular Epidemiology, Department of Public Health, Aarhus University, Denmark. The statistical significance level was set to $p \leq 0.05$. For multiple comparison correction, the statistical level was set to FDR $q_{\text {value }}<0.25$.

\section{Results \\ Characteristics of the study population}

Table 2 shows the descriptive characteristics of the study population. Most children were male and born at term. The majority of AF samples were obtained in gestational week 15 . More than $62 \%$ of mothers were carrying at least two children. The demographics of cases and controls were similar. The percentages of Apgar scores $\geq 7$ were above $98 \%$ both in case and control groups, indicating that almost all participants in this study were classified as healthy at birth. ASD cases were significantly more co-diagnosed with congenital malformation $(29.30 \%$ vs. $8.10 \%, p<0.0001)$.

\section{Levels of perfluoroalkyl substances (PFAS)}

PFOS, PFOSA, PFHxS, PFOA, and PFDoA were detectable in $46.6 \%, 35.2 \%, 4.50 \%, 81.8 \%$, and $1.10 \%$ of the AF samples, respectively; the remaining PFAS congeners were under the limit of quantification (Additional file 1). For the control group, no significant correlations between PFAS congeners and potential confounders were observed, and PFOS was significantly correlated to PFOA $(r=0.620, p<0.0001)$, PFHxS $(r=0.330, p=0.02)$, and borderline to PFOSA $(r=0.300, p=0.056)$ (data not shown).

Cases significantly differed from controls with lower levels of PFOS $(p=0.015)$ and PPFSA $(p=0.011)$ as well as all the tested PFAS ( $\sum$ PFSA $+\sum$ PFCA $)(p=0.021)$ (Table 3). After false discovery rate correction, the significances persisted (FDR $q_{\text {value }}=0.189$, Table 3 ).

\section{Levels of elements and heavy metals}

Among the measured 59 elements and metals, 16 elements including iron $(\mathrm{Fe})$, copper $(\mathrm{Cu})$, zinc $(\mathrm{Zn})$ and selenium (Se) were detectable in all AF samples, while 8 elements, including mercury $(\mathrm{Hg})$ and silver $(\mathrm{Ag})$, were not detectable in any AF samples. The metals of interest such as chromium $(\mathrm{Cr})$, lead $(\mathrm{Pb})$, arsenic (As), manganese $(\mathrm{Mn})$, and cadmium $(\mathrm{Cd})$ were detected in $98.9 \%$, $34.1 \%, 22.7 \%, 18.2 \%$, and $12.5 \%$ of the AF samples, respectively (Additional file 2).

Similar levels of elements and heavy metals between ASD cases and controls were observed (Table 3).

\section{Levels of endogenous sex hormones and the combined effect of endogenous hormones and EDCs on the receptor transactivation}

For the endogenous sex hormone levels, no significant difference between ASD cases and controls was observed. The ratio of testosterone to E2 was slightly higher in ASD cases compared to controls (Table 4). 
Table 2 Characteristics of the study population

\begin{tabular}{|c|c|c|c|}
\hline Characteristic & ASD cases $(n=75)$ & Controls $(n=135)$ & $p$ value \\
\hline Mother's age at delivery (median, min-max, year) & $34(17-41)$ & $35(21-44)$ & 0.218 \\
\hline Father's age at delivery (median, min-max, year) & $35(19-53)$ & $35(20-58)$ & 0.362 \\
\hline Gestational week at sampling (median, min-max) & $15(11-20)$ & $15(10-29)$ & 0.426 \\
\hline Parity $(n, \%)$ & & & 0.797 \\
\hline 1st child & $28(37.30 \%)$ & $48(35.6 \%)$ & \\
\hline$\geq$ 2nd child & $47(62.70 \%)$ & $87(64.4 \%)$ & \\
\hline Gestational age at birth ( $n, \%)$ & & & 0.424 \\
\hline Preterm (<260 days) & 7 (9.30\%) & $15(11.20 \%)$ & \\
\hline Term (260 days -294 days) & $67(89.30 \%)$ & $113(84.30 \%)$ & \\
\hline Post-term (> 295 days) & $1(1.30 \%)$ & $6(4.50 \%)$ & \\
\hline Gender of the children $(n, \%)$ & & & 0.731 \\
\hline Female & $13(17.30 \%)$ & $26(19.30 \%)$ & \\
\hline Male & $62(82.70 \%)$ & 109 (80.70\%) & \\
\hline Birth weight of the children $(n, \%)$ & & & 0.521 \\
\hline$<2500 \mathrm{~g}$ & $3(4.10 \%)$ & $10(7.50 \%)$ & \\
\hline $2500 \mathrm{~g}-4000 \mathrm{~g}$ & $57(77.00 \%)$ & $95(70.90 \%)$ & \\
\hline$>4000 \mathrm{~g}$ & $14(18.90 \%)$ & $29(21.60 \%)$ & \\
\hline Apgar score of the children $(n, \%)$ & & & 0.952 \\
\hline$\geq 7$ & $70(98.60 \%)$ & $130(98.50 \%)$ & \\
\hline$<7$ & $1(1.40 \%)$ & $2(1.50 \%)$ & \\
\hline Congenital malformation of the children $(n, \%)$ & & & $<0.0001$ \\
\hline No & $53(70.70 \%)$ & $124(91.90 \%)$ & \\
\hline Yes & $22(29.30 \%)$ & $11(8.10 \%)$ & \\
\hline
\end{tabular}

Student $t$ test and chi-square test were used to compare the difference between cases and controls. Italicized values indicate statistically significant

The effect of AF samples on the receptor transactivation is given as the corresponding receptor ligand equivalent (for detailed explanation see Table 1). We observed that the combined effect of endogenous estrogen and EDCs on ER (ER-EEQ) and EDC-induced xenoestrogenic effect (EDC-EEQ) was slightly lower in cases, but the difference was not significant (Table 4). We observed no significant differences between the ASD cases and controls for the combined androgenic effect (AR-AEQ) and neither for TH-like activity (T3-ThEQ) and dioxin-like activity (AhR-TEQ) (Table 4).

\section{Association of ASD risk and levels of chemicals}

As given in Table 5, for the crude and adjusted data, we observed an inverse association between PFOS level in AF and ASD risk (adjusted OR 0.410, 95\% CI 0.140$0.967, p=0.042$ ) (Table 5). However, after false discovery rate correction, the significance of PFOS disappeared (FDR $q_{\text {value }}=0.437$, Table 5).

We observed no clear association for nutrient elements such as $\mathrm{Fe}, \mathrm{Cu}, \mathrm{Zn}, \mathrm{Se}$, and I with ASD risk (Table 6). However, although no significant association between toxic metals and ASD risk was observed, we noticed that adjusted ORs were 1.496 (95\% CI 0.924, 2.424; $p=0.101$ ) for As and 1.300 (95\% CI 0.657, 2.575; $p=0.451$ ) for $\mathrm{Pb}$, respectively (Table 6).

After stratifying by the children's gender and removing cases with congenital malformations, the results regarding PFAS, metals/elements, and ASD risk were not changed (Additional files 3 and 4).

\section{Association of ASD risk with the levels of sex hormones} and the combined AF-induced receptor effect biomarkers The logistic regression analyses showed a weak association between AF testosterone level and ASD risk (adjusted OR 1.002; 95\% CI 1.000, 1.004; $p=0.050$ ) (Table 7). However, after false discovery rate correction, this significant association did not persist $\left(\right.$ FDR $q_{\text {value }}=$ 0.437, Table 7).

We found no significant association between ASD risk and AF-induced receptor transactivities. We noticed, however, that the adjusted OR for the ratio of AR-AEQ/ ER-EEQ was 2.176 (95\% CI 0.115, 41.15). We observed no obvious associations between ASD risk and dioxin-like activity (AhR-TEQ) and TH-like activity (Table 7). Stratifying by children's gender and removing 
Table 3 Levels of perfluoroalkylated substances and elements in amniotic fluid

\begin{tabular}{|c|c|c|c|c|c|c|c|c|}
\hline & \multicolumn{3}{|c|}{ ASD cases } & \multicolumn{3}{|c|}{ Control } & \multirow[b]{2}{*}{$p$} & \multirow[b]{2}{*}{ FDR ( $\left.q_{\text {value }}\right)$} \\
\hline & $n$ & Median & Min-max & $n$ & Median & Min-max & & \\
\hline \multicolumn{9}{|l|}{ PFAS (ng/mL) } \\
\hline PFOS & 37 & 0.61 & $0.61-2.98$ & 51 & 1.44 & $0.61-4.22$ & 0.015 & 0.189 \\
\hline PFOSA & 37 & 0.60 & $0.60-13.30$ & 51 & 0.60 & $0.60-19.00$ & 0.152 & 0.638 \\
\hline PFOA & 37 & 0.29 & $0.10-0.78$ & 51 & 0.32 & $0.10-1.86$ & 0.516 & 0.764 \\
\hline$\sum$ PFSA & 37 & 1.56 & $1.56-15.40$ & 51 & 2.60 & $1.56-21.70$ & 0.011 & 0.189 \\
\hline$\Sigma P F C A$ & 37 & 1.54 & $1.35-2.03$ & 51 & 1.57 & $1.35-3.11$ & 0.489 & 0.764 \\
\hline$\sum \mathrm{PFSA}+\sum \mathrm{PFCA}$ & 37 & 3.26 & $2.91-17.37$ & 51 & 4.23 & $2.91-23.26$ & 0.021 & 0.189 \\
\hline \multicolumn{9}{|l|}{ Elements ( $\mu \mathrm{g} / \mathrm{L})$} \\
\hline $\mathrm{Fe}$ & 37 & 259.00 & $16.00-778.0$ & 51 & 270.00 & $128.00-2575$ & 0.571 & 0.764 \\
\hline $\mathrm{Cu}$ & 37 & 89.15 & $45.62-206.10$ & 51 & 100.40 & $53.53-223.10$ & 0.189 & 0.638 \\
\hline $\mathrm{Zn}$ & 37 & 97.90 & 34.69-754.5 & 51 & 102.00 & $30.90-1216$ & 0.557 & 0.764 \\
\hline $\mathrm{Se}$ & 37 & 4.43 & $2.250-7.130$ & 51 & 4.55 & $2.980-7.27$ & 0.758 & 0.861 \\
\hline I & 37 & 1.88 & $1.88-94.68$ & 51 & 1.88 & $1.88-195.40$ & 0.765 & 0.861 \\
\hline $\mathrm{Cr}$ & 37 & 0.75 & $0.16-3.85$ & 51 & 0.73 & $0.31-2.21$ & 0.365 & 0.704 \\
\hline $\mathrm{Mn}$ & 37 & 0.65 & $0.65-25.89$ & 51 & 0.65 & $0.65-5.26$ & 0.826 & 0.892 \\
\hline As & 37 & 1.33 & $1.33-6.19$ & 51 & 1.33 & $1.33-4.96$ & 0.328 & 0.704 \\
\hline $\mathrm{Cd}$ & 37 & 0.02 & $0.02-1.92$ & 51 & 0.02 & $0.02-0.14$ & 0.648 & 0.795 \\
\hline $\mathrm{Pb}$ & 37 & 0.22 & $0.22-2.27$ & 51 & 0.22 & $0.22-5.30$ & 0.526 & 0.764 \\
\hline
\end{tabular}

¿PFSA perfluorosulfonated acids which was the sum of PFOS, PFHpS, PFBS, PFHXS, PFDS, and PFOSA, $\angle P F C A$ perfluorocarboxylated acids which was the sum of PFOA, PFHXA, PFHpA, PFNA, PFDA, PFUnA, PFDoA, and PFPeA, FDR ( $\left.q_{\text {value }}\right)$ false discovery rate. The difference between cases and controls was compared using non-parametric Mann-Whitney test. Italicized values indicate statistically significant $\left(p \leq 0.05\right.$ and FDR $\left.q_{\mathrm{value}}<0.25\right)$

Table 4 Levels of hormones and receptor transactivities in amniotic fluid

\begin{tabular}{|c|c|c|c|c|c|c|c|c|}
\hline \multirow[t]{2}{*}{ Parameter } & \multicolumn{3}{|c|}{ ASD case } & \multicolumn{3}{|c|}{ Control } & \multirow[b]{2}{*}{$p$} & \multirow[b]{2}{*}{ FDR ( $\left.q_{\text {value }}\right)$} \\
\hline & $n$ & Median & Min-Max & $N$ & Median & Min-Max & & \\
\hline E2 $(p g / m L)$ & 68 & 287.4 & $78.72-2778$ & 128 & 311.9 & $55.02-1005$ & 0.337 & 0.704 \\
\hline Testosterone (pg/mL) & 67 & 383.6 & 47.30-1393 & 130 & 366.3 & $80.47-1090$ & 0.173 & 0.638 \\
\hline Testosterone/E2 ratio & 66 & 1.49 & $0.21-7.41$ & 128 & 1.25 & $0.14-4.310$ & 0.222 & 0.666 \\
\hline ER-EEQ (pg E2/mL) & 75 & 470.9 & $204.1-1308$ & 135 & 545.8 & $149.0-1308$ & 0.329 & 0.704 \\
\hline EDC-EEQ (pg E2/mL) & 68 & 168.5 & $0.28-1226$ & 128 & 214.4 & $2.72-1165$ & 0.162 & 0.638 \\
\hline AR-AEQ (pg DHT/mL) & 75 & 62.60 & $23.90-137.3$ & 135 & 62.50 & $16.90-290.4$ & 0.910 & 0.910 \\
\hline EDC-AEQ (pg DHT/mL) & 67 & 22.56 & $1.000-100.4$ & 130 & 28.45 & $1.34-274.0$ & 0.167 & 0.638 \\
\hline AR-AEQ/ER-EEQ & 75 & 0.13 & $0.02-0.48$ & 135 & 0.11 & $0.02-0.98$ & 0.343 & 0.704 \\
\hline EDC-AEQ/EDCs-EEQ & 61 & 0.18 & $0.01-59.10$ & 117 & 0.086 & $0.003-26.21$ & 0.515 & 0.764 \\
\hline T3-ThEQ (ng T3/mL) & 74 & 2.36 & $0.10-17.14$ & 133 & 2.41 & $0-6.60$ & 0.594 & 0.764 \\
\hline AhR-TEQ (pg TCDD/mL) & 37 & 0.24 & $0-1.310$ & 51 & 0.15 & $0-2.10$ & 0.907 & 0.910 \\
\hline
\end{tabular}

E2 $17 \beta$-estradiol, ER-EEQ the combined effect on ER of endogenous estrogen and xeno-estrogens (EDCs) given as estradiol equivalent, EDCs-EEQ the integrated estrogenic effect induced only by xeno-estrogens (EDCs) alone given as estradiol equivalent, $D H T$ dihydrotestosterone, $A R-A E Q$ the combined effect on AR of endogenous androgens and xeno-androgens (EDCs) given as androgen equivalent, $E D C-A E Q$ the integrated androgenic effect induced only by xeno-androgens (EDCs) alone given as androgen equivalent, T3 L-3,5,3'-triiiodothyronine, T3-ThEQ the combined proliferation effect (PE) of endogenous thyroid and xeno-thyroid hormone-like compounds (EDCs) given as thyroid equivalent, AhR-TEQ the combined effect on AhR of dioxin-like compounds given as TCDD equivalent, FDR $\left(q_{\text {value }}\right)$ false discovery rate. See the "Methods" section and Table 1 for the different calculations. The difference between cases and controls was compared using non-parametric Mann-Whitney test 
Table 5 Odds ratio and 95\% confidence intervals for ASD according to PFAS in amniotic fluid

\begin{tabular}{|c|c|c|c|c|c|c|c|}
\hline & \multicolumn{3}{|l|}{ Crude } & \multicolumn{4}{|l|}{ Adjusted $^{a}$} \\
\hline & $n$ (cases/controls) & OR $(95 \% \mathrm{Cl})$ & $p$ & $n$ (cases/controls) & OR $(95 \% \mathrm{Cl})$ & $p$ & FDR ( $q_{\text {value }}$ \\
\hline PFOS (ng/mL) & $37 / 51$ & $0.460(0.230,0.921)$ & 0.028 & $37 / 50$ & $0.410(0.174,0.967)$ & 0.042 & 0.437 \\
\hline PFOSA (ng/mL) & $37 / 51$ & $0.913(0.797,1.046)$ & 0.189 & $37 / 50$ & $0.918(0.789,1.069)$ & 0.272 & 0.565 \\
\hline $\mathrm{PFOA}(\mathrm{ng} / \mathrm{mL})$ & $37 / 51$ & $0.335(0.044,2.559)$ & 0.292 & $37 / 50$ & $0.164(0.013,2.126)$ & 0.167 & 0.437 \\
\hline$\sum$ PFSA (ng/mL) & $37 / 51$ & $0.894(0.777,1.028)$ & 0.115 & $37 / 50$ & $0.900(0.771,1.049)$ & 0.178 & 0.437 \\
\hline$\sum$ PFCA (ng/mL) & $37 / 51$ & $0.299(0.041,2.160)$ & 0.232 & $37 / 50$ & $0.150(0.013,1.760)$ & 0.131 & 0.437 \\
\hline$\sum P F S A+\sum P F C A(n g / m L)$ & $37 / 51$ & $0.894(0.779,1.025)$ & 0.107 & $37 / 50$ & $0.896(0.770,1.044)$ & 0.158 & 0.437 \\
\hline
\end{tabular}

FDR ( $\left.q_{\text {value }}\right)$ false discovery rate. Italicized values indicate statistically significant $\left(p \leq 0.05\right.$ and FDR $\left.q_{\text {value }}<0.25\right)$

${ }^{a}$ Adjusted for children's birth year, children's sex, mother age at delivery, father age at child birth, birth weight, gestational week at sampling, gestational age at birth, Apgar score, parity, and congenital malformation

the congenital malformations did not alter the results (Additional files 4 and 5).

\section{Correlations between PFAS levels and combined AF- induced receptor effect biomarkers}

In general, PFAS positively correlated with the ER-EEQ and EDC-EEQ being significant for PFOS, PFOSA, $\Sigma$ PFSA, and all tested PFAS ( $\sum$ PFSA $+\sum$ PFCA). In contrast, PFAS inversely correlated with AR-AEQ as well as EDC-AEQ, being significant for cases (Table 8).

\section{Principal component analysis}

Table 9 shows the loadings on the first seven principal component (PC) variables which account for $64.6 \%$ of the variation in the original data. Figure 2 is the graphical representation of the loading on the first three PC variables which accounts for $32.40 \%$ of the total variation.

Summary statistics for the biomarkers with a detection frequency $>10 \%$ used in the PCA are found in the Additional file 6. Mann-Whitney test on the PCA scores for each component revealed that only the first principal component (PC-1), dominated by PFAS congeners, was significantly different between cases and controls (Additional file 7).

Logistic regression analysis showed a significantly negative association between ASD risk and first component (PC-1), including PFAS congeners, $\mathrm{Cu}, \mathrm{Fe}$, and ER-EEQ, both before and after adjustment for potential confounders (Table 10). After false discovery rate correction, the significance still persisted (adjusted $\mathrm{OR}=0.100$; $95 \%$ CI $0.016,0.630 ; p=0.014, \quad$ FDR $q_{\text {value }}=0.098$, Table 10). The other identified principal components did not show significant associations with ASD risk.

After stratifying by children's gender, the significant association of PC-1 and ASD risk disappeared which may due to reduced sample size (Additional file 8). When removing cases with congenital malformation, similar significant association between PC-1 and risk of ASD was found (Additional file 9).

\section{Discussion}

The present study measured the levels of elements/ metals and POPs such as PFAS in AF and receptor

Table 6 Odds ratio and 95\% confidence intervals for ASD according to elements in amniotic fluid

\begin{tabular}{|c|c|c|c|c|c|c|c|}
\hline & Crude & & & Adjusted $^{\mathrm{a}}$ & & & \\
\hline & $n$ (cases/controls) & OR $(95 \% \mathrm{Cl})$ & $p$ & $n$ (cases/controls) & OR $(95 \% \mathrm{Cl})$ & p & FDR ( $\left.q_{\text {value }}\right)$ \\
\hline $\mathrm{Fe}(\mu \mathrm{g} / \mathrm{L})$ & $37 / 51$ & $0.999(0.996,1.001)$ & 0.255 & $37 / 50$ & $0.999(0.997,1.001)$ & 0.449 & 0.677 \\
\hline $\mathrm{Cu}(\mu \mathrm{g} / \mathrm{L})$ & $37 / 51$ & $0.991(0.978,1.005)$ & 0.211 & $37 / 50$ & $0.997(0.981,1.012)$ & 0.685 & 0.771 \\
\hline Zn $(\mu \mathrm{g} / \mathrm{L})$ & $37 / 51$ & $0.999(0.996,1.002)$ & 0.673 & $37 / 50$ & $0.999(0.995,1.002)$ & 0.491 & 0.698 \\
\hline $\mathrm{Se}(\mu \mathrm{g} / \mathrm{L})$ & $37 / 51$ & $0.977(0.649,1.469)$ & 0.910 & $37 / 50$ & $1.058(0.644,1.740)$ & 0.823 & 0.823 \\
\hline I ( $\mu \mathrm{g} / \mathrm{L})$ & $37 / 51$ & $0.996(0.978,1.014)$ & 0.674 & $37 / 50$ & $0.981(0.959,1.003)$ & 0.087 & 0.437 \\
\hline $\mathrm{Cr}(\mu \mathrm{g} / \mathrm{L})$ & $37 / 51$ & $1.019(0.403,2.576)$ & 0.968 & $37 / 50$ & $0.377(0.051,2.764)$ & 0.337 & 0.650 \\
\hline $\mathrm{Mn}(\mu \mathrm{g} / \mathrm{L})$ & $37 / 51$ & $1.106(0.878,1.394)$ & 0.393 & $37 / 50$ & $1.065(0.841,1.347)$ & 0.602 & 0.771 \\
\hline As $(\mu \mathrm{g} / \mathrm{L})$ & $37 / 51$ & $1.257(0.856,1.846)$ & 0.244 & $37 / 50$ & $1.496(0.924,2.424)$ & 0.101 & 0.437 \\
\hline $\mathrm{Cd}(\mu \mathrm{g} / \mathrm{L})$ & $37 / 51$ & $4.418(0.099,197)$ & 0.444 & $37 / 50$ & $5.935(0.101,349.3)$ & 0.392 & 0.662 \\
\hline $\mathrm{Pb}(\mu \mathrm{g} / \mathrm{L})$ & $37 / 51$ & $1.086(0.615,1.918)$ & 0.776 & $37 / 50$ & $1.300(0.657,2.575)$ & 0.451 & 0.677 \\
\hline
\end{tabular}

FDR ( $\left.q_{\text {value }}\right)$ false discovery rate

adjusted for children's birth year, children's sex, mother age at delivery, father age at child birth, birth weight, gestational age at birth, gestational week at sampling, Apgar score, parity, and congenital malformation 
Table 7 Odds ratio and 95\% confidence intervals for ASD according to hormone level and receptor transactivity induced by amniotic fluid

\begin{tabular}{|c|c|c|c|c|c|c|c|}
\hline & Crude & & & Adjusted $^{a}$ & & & \\
\hline & $n$ (cases/controls) & OR $(95 \% \mathrm{Cl})$ & $p$ & $n$ (cases/controls) & OR $(95 \% \mathrm{Cl})$ & $p$ & FDR ( $\left.q_{\text {value }}\right)$ \\
\hline E2 $(p g / m L)$ & $68 / 128$ & $1.000(0.999,1.001)$ & 0.629 & $65 / 125$ & $1.000(0.999,1.001)$ & 0.669 & 0.771 \\
\hline Testosterone (pg/mL) & $67 / 130$ & $1.001(1.000,1.003)$ & 0.050 & $64 / 127$ & $1.002(1.000,1.004)$ & 0.050 & 0.437 \\
\hline Testosterone/E2 & $66 / 128$ & $1.257(0.950,1.664)$ & 0.110 & $63 / 125$ & $1.350(0.935,1.949)$ & 0.110 & 0.437 \\
\hline ER-EEQ (pg E2/mL) & $75 / 135$ & $1.000(0.999,1.000)$ & 0.358 & $71 / 132$ & $1.000(0.999,1.000)$ & 0.222 & 0.500 \\
\hline EDCs-EEQ (pg E2/mL) & $68 / 128$ & $0.999(0.998,1.000)$ & 0.112 & $65 / 125$ & $0.999(0.998,1.000)$ & 0.089 & 0.437 \\
\hline AR-AEQ (pg DHT/mL) & $75 / 135$ & $0.995(0.985,1.006)$ & 0.389 & $71 / 132$ & $0.997(0.985,1.010)$ & 0.650 & 0.771 \\
\hline EDCs-AEQ (pg DHT/mL) & $67 / 130$ & $0.989(0.976,1.002)$ & 0.109 & $64 / 127$ & $0.989(0.974,1.005)$ & 0.169 & 0.437 \\
\hline AR-AEQ/ER-EEQ & $75 / 135$ & $1.269(0.104,15.479)$ & 0.852 & $71 / 132$ & $2.176(0.115,41.15)$ & 0.604 & 0.771 \\
\hline EDCs-AEQ/EDCs-EEQ & $66 / 128$ & $1.022(0.794,1.552)$ & 0.423 & $63 / 125$ & $1.032(0.974,1.092)$ & 0.285 & 0.662 \\
\hline T3-ThEQ (ng T3/mL) & $74 / 133$ & $1.094(0.874,1.369)$ & 0.434 & $71 / 130$ & $1.036(0.806,1.332)$ & 0.784 & 0.822 \\
\hline AhR-TEQ (pgTCDD/mL) & $37 / 51$ & $0.786(0.238,2.589)$ & 0.692 & $36 / 50$ & $0.792(0.192,3.270)$ & 0.747 & 0.822 \\
\hline
\end{tabular}

E2 $17 \beta$-Estradiol, ER-EEQ the combined effect on ER of endogenous estrogen and xeno-estrogens (EDCs) given as estradiol equivalent, EDC-EEQ the integrated estrogenic effect induced only by xeno-estrogens (EDCs) alone given as estradiol equivalent, $D H T$ dihydrotestosterone, $A R-A E Q$ the combined effect on AR of endogenous androgens and xeno-androgens (EDCs) given as androgen equivalent, $E D C-A E Q$ the integrated androgenic effect induced only by xeno-androgens (EDCs) alone given as androgen equivalent, $T 3$ L-3,5,3'-triiiodothyronine, T3-ThEQ the combined proliferation effect (PE) of endogenous thyroid and xeno-thyroid hormone-like compounds (EDCs) given as thyroid equivalent, AhR-TEQ the combined effect on AhR of dioxin-like compounds given as TCDD equivalent, FDR $\left(q_{\text {value }}\right)$ false discovery rate. Italicized values indicate statistically significant $\left(p \leq 0.05\right.$ and FDR $q_{\text {value }}<0.25$ )

${ }^{a}$ Adjusted for children's birth year, children's sex, mother age at delivery, father age at child birth, birth weight, gestational age at birth, gestational week at sampling, Apgar score, parity, and congenital malformation

transactivities induced by AF, and explored their association with diagnoses of child ASD. We detected PFOS and PFOA in more than $46 \%$ of the AF samples and As, $\mathrm{Cd}$, and $\mathrm{Pb}$ in up to $34 \%$ of the $\mathrm{AF}$ samples, suggesting that in addition to blood borne in utero exposure, the fetus also ingests and is exposed to low levels of PFAS and heavy metals. However, the lipophilic POPs, such as PCBs, PBDEs, and OCPs, were not detectable in AF. The combined biomarkers of effect such as ER-, AR-, AhR-, and TH-like activity were determined in the AF samples, indicating the presence of EDCs in amniotic fluid. Compared to the controls, ASD cases showed a different pattern regarding the AF levels of PFAS, heavy metals, and receptor activities. Although it lacks robust, statistically significant associations between EDCs and ASD risk, this study suggests a role of prenatal exposure to EDCs on the risk of ASD. But further studies are needed, especially for their effect interfering with the function of, e.g., sex hormone receptors such as ER and AR.

Stein et al. reported that PFOA and PFOS were detected in $86 \%$ and $32 \%$ of AF samples and suggested that PFOA was more commonly detected in AF than PFOS [76]. Similarly, in the present study, PFOA was detectable in $82 \%$ and PFOS was only detectable in $47 \%$ of the AF samples collected during 1995-1999, suggesting that most of the pregnant Danish women were exposed to both PFOA and PFOS. In the present study, the median PFOS level in AF sampling during 1995-1999 from male offspring pregnancies in the control group was $0.61 \mathrm{ng} /$ $\mathrm{ml}$, being lower than reported by Jensen et al. $(1.1 \mathrm{ng} /$ $\mathrm{ml}$ ) in their samples collected during 1980-1996 [64], suggesting a decreasing PFOS exposure in Denmark after 1996. However, compared to the pregnant women in the USA during 2005-2008 [76], the AF level of PFOS in the control group in this study (1995-1999) was higher (1.44 vs $0.4 \mathrm{ng} / \mathrm{ml}$ ) but similar for PFOA (0.32 vs $0.3 \mathrm{ng} / \mathrm{ml}$ ), supporting an effective action of phase out of PFOS and PFOA in the USA [77]. The decreasing trend of PFOS concentrations observed in most European and North American studies follows the phasing out in 2000-2002 of perfluorooctanesulfonyl-fluoride-based (POSF) production by 3 M [78, 79]. Similarly, a decreasing trend for PFOA serum concentrations has also been observed in several studies, indicating that exposure pathways of these two compounds are historically linked $[79,80]$. However, the production of PFOA precursor materials (ammonium perfluorooctanoate and fluorotelomer alcohols) has remained constant until 2006 [80]. Stein et al. did not detect PFOSA in the AF samples of pregnant women in the USA [76], while PFOSA was detectable in $35 \%$ of the AF samples in the present Danish population. PFOSA is a synthetic compound used to repel grease and water in food packing along with other consumer applications, and it breaks down to PFOS [81], which might partly explain the higher level of PFOS in the present study compared to pregnant women in the USA [76]. PFOSA was reported to have developmental neurotoxicity in vitro [82]. Although no obvious association was seen between PFOSA and ASD risk in this 
Table 8 The correlation among PFAS levels in amniotic fluid and receptor transactivity induced by AF

\begin{tabular}{|c|c|c|c|c|c|c|c|c|c|c|c|c|c|c|c|c|c|c|}
\hline & \multicolumn{3}{|c|}{ ER-EEQ } & \multicolumn{3}{|c|}{ EDC-EEQ } & \multicolumn{3}{|c|}{ AR-AEQ } & \multicolumn{3}{|c|}{ EDC-AEQ } & \multicolumn{3}{|c|}{ T3-ThEQ } & \multicolumn{3}{|c|}{ AhR-TEQ } \\
\hline & $n$ & $r_{\mathrm{s}}$ & $p$ & $n$ & $r_{s}$ & $p$ & $n$ & $r_{\mathrm{s}}$ & $p$ & $n$ & $r_{5}$ & $p$ & $n$ & $r_{\mathrm{s}}$ & $p$ & $n$ & $r_{\mathrm{s}}$ & $p$ \\
\hline \multicolumn{19}{|l|}{ ASD cases } \\
\hline PFOS & 37 & 0.522 & 0.001 & 30 & 0.246 & 0.189 & 37 & 0.258 & 0.124 & 30 & 0.466 & 0.009 & 34 & 0.145 & 0.398 & 37 & 0.097 & 0.569 \\
\hline PFOSA & 37 & 0.237 & 0.158 & 30 & 0.199 & 0.292 & 37 & -0.391 & 0.017 & 30 & -0.163 & 0.390 & 36 & -0.038 & 0.825 & 37 & 0.140 & 0.410 \\
\hline PFOA & 37 & 0.225 & 0.180 & 30 & 0.317 & 0.087 & 37 & 0.007 & 0.968 & 30 & -0.399 & 0.029 & 34 & 0.039 & 0.822 & 37 & 0.125 & 0.462 \\
\hline$\sum$ PFSA & 37 & 0.332 & 0.045 & 30 & 0.158 & 0.403 & 37 & -0.305 & 0.066 & 30 & -0.310 & 0.095 & 34 & -0.026 & 0.882 & 37 & 0.100 & 0.555 \\
\hline$\sum \mathrm{PFCA}$ & 37 & 0.225 & 0.180 & 30 & 0.317 & 0.087 & 37 & 0.007 & 0.968 & 30 & -0.399 & 0.029 & 34 & 0.039 & 0.822 & 37 & 0.125 & 0.462 \\
\hline$\sum P F S A+\sum P F C A$ & 37 & 0.343 & 0.038 & 30 & 0.330 & 0.075 & 37 & -0.194 & 0.249 & 30 & -0.318 & 0.087 & 34 & -0.005 & 0.978 & 37 & 0.138 & 0.417 \\
\hline \multicolumn{19}{|l|}{ Controls } \\
\hline PFOS & 51 & 0.156 & 0.276 & 44 & 0.273 & 0.073 & 51 & -0.082 & 0.565 & 46 & -0.010 & 0.947 & 48 & -0.004 & 0.979 & 51 & -0.065 & 0.649 \\
\hline PFOSA & 51 & 0.220 & 0.121 & 44 & 0.356 & 0.018 & 51 & -0.160 & 0.263 & 46 & -0.108 & 0.476 & 49 & -0.221 & 0.127 & 51 & -0.273 & 0.105 \\
\hline PFOA & 51 & 0.104 & 0.469 & 44 & 0.097 & 0.530 & 51 & -0.002 & 0.989 & 46 & 0.048 & 0.751 & 48 & 0.209 & 0.150 & 51 & 0.148 & 0.300 \\
\hline$\sum \mathrm{PFSA}$ & 51 & 0.321 & 0.021 & 44 & 0.442 & 0.003 & 51 & -0.160 & 0.263 & 46 & -0.071 & 0.641 & 48 & -0.186 & 0.202 & 51 & -0.253 & 0.074 \\
\hline$\sum$ PFCA & 51 & 0.100 & 0.487 & 44 & 0.093 & 0.548 & 51 & -0.005 & 0.974 & 46 & 0.051 & 0.736 & 48 & 0.203 & 0.161 & 51 & 0.142 & 0.322 \\
\hline$\sum \mathrm{PFSA}+\sum \mathrm{PFCA}$ & 51 & 0.332 & 0.017 & 44 & 0.438 & 0.003 & 51 & -0.146 & 0.305 & 46 & -0.047 & 0.757 & 48 & -0.148 & 0.309 & 51 & -0.217 & 0.125 \\
\hline \multicolumn{19}{|l|}{ All } \\
\hline PFOS & 88 & 0.305 & 0.004 & 74 & 0.251 & 0.031 & 88 & -0.182 & 0.090 & 76 & -0.085 & 0.465 & 85 & 0.18 & 0.871 & 88 & 0.015 & 0.891 \\
\hline PFOSA & 88 & 0.224 & 0.036 & 74 & 0.304 & 0.009 & 88 & -0.258 & 0.015 & 76 & -0.114 & 0.328 & 85 & -0.141 & 0.197 & 88 & -0.120 & 0.267 \\
\hline PFOA & 88 & 0.194 & 0.070 & 74 & 0.212 & 0.070 & 88 & -0.031 & 0.777 & 76 & -0.127 & 0.274 & 82 & 0.117 & 0.285 & 88 & 0.145 & 0.178 \\
\hline$\sum$ PFSA & 88 & 0.342 & 0.001 & 74 & 0.354 & 0.02 & 88 & -0.259 & 0.015 & 76 & -0.114 & 0.328 & 82 & -0.119 & 0.278 & 88 & -0.106 & 0.326 \\
\hline$\sum \mathrm{PFCA}$ & 88 & 0.191 & 0.074 & 74 & 0.210 & 0.073 & 88 & -0.033 & 0.758 & 76 & -0.123 & 0.288 & 82 & 0.115 & 0.294 & 88 & 0.142 & 0.187 \\
\hline$\sum P F S A+\sum P F C A$ & 88 & 0.361 & 0.001 & 74 & 0.398 & $<0.001$ & 88 & -0.218 & 0.042 & 76 & -0.103 & 0.374 & 82 & -0.088 & 0.423 & 88 & -0.065 & 0.545 \\
\hline
\end{tabular}

$E R$-EEQ the combined effect on ER of endogenous estrogen and xeno-estrogens (EDCs) given as estradiol equivalent, EDC-EEQ the integrated estrogenic effect induced only by xeno-estrogens (EDCs) alone given as estradiol equivalent, $D H T$ dihydrotestosterone, $A R$-AEQ the combined effect on AR of endogenous androgens and xeno-androgens (EDCs) given as androgen equivalent, EDC-AEQ the integrated androgenic effect induced only by xeno-androgens (EDCs) alone given as androgen equivalent, T3 L-3,5,3'-triiiodothyronine, T3-ThEQ the combined proliferation effect (PE) of endogenous thyroid and xeno-thyroid hormone-like compounds (EDCs) given as thyroid equivalent, AhR-TEQ the combined effect on AhR of dioxin-like compounds given as TCDD equivalent, $r_{s}$, Spearman's rho correlation coefficient. Italicized values indicate statistically significant $(p \leq 0.05)$

study, more research is warranted to study the effect of PFOSA.

The testosterone and estradiol were detectable in the AF samples. In ASD cases, the ratio of testosterone level over E2 level in AF was non-significantly higher compared to the controls. Baron-Cohen and co-workers also reported that autism cases had higher levels of testosterone and other precursor steroid hormones (progesterone, 17 $\alpha$-hydroxy-progesterone, and androstenedione) in the AF samples from same cohort (HBC) [14]. The fetal testosterone theory hypothesizes that higher levels of testosterone in AF pushes brain development towards improved ability to emphasize systemizing, which is a typical male trait and diminish female trait emphasizing [83]. An earlier study suggested that high levels of fetal testosterone could produce behaviors relevant to those observed for autism [84]. Auyeung et al. compared prenatal and postnatal testosterone and estradiol levels in relation to autistic traits in 18- to 24-month-old children. They found that prenatal (but not postnatal) androgen exposure, coinciding with the critical period for sexual differentiation of the brain, was associated with the development of autistic traits in 18- to 24-month-old toddlers. This suggests that prenatal, organizational effects of androgen hormones influence the development of autistic traits in later life [85]. Other studies reported that estrogen can be protective while androgens potentiate ASD [86, 87], supporting our observation of lower levels of endogenous estrogen E2 and higher endogenous androgen testosterone found in ASD cases. Furthermore, in support to our study, a higher ratio of testosterone to estradiol in AF was suggested to be associated with ASD [58],

EDCs deserve consideration as candidate risk factors for ASD because of their potential to alter hormonal axis functions that play an important role in neurodevelopment. However, few studies have examined the link between EDC exposure, especially for PFAS, and the risk of ASD or autistic behaviors. A cross-sectional study suggested that there might be a protective association between exposure to PFAS and cognition in older adults [88]. A prospective study showed better cognitive 
Table 9 Rotated factor loading of components identified by principal component analysis (PCA)

\begin{tabular}{|c|c|c|c|c|}
\hline Interpreted biomarker component & Biomarker name & Factor loading $^{a}$ & Explained variance (\%) & Explained variance cumulative (\%) \\
\hline \multirow[t]{7}{*}{$\overline{P C-1}$} & PFOS & 0.853 & 12.27 & 12.27 \\
\hline & PFOA & 0.696 & & \\
\hline & PFOSA & 0.523 & & \\
\hline & $\mathrm{Cu}$ & 0.452 & & \\
\hline & AR-AEQ & -0.386 & & \\
\hline & ER-EEQ & 0.363 & & \\
\hline & $\mathrm{Fe}$ & 0.358 & & \\
\hline \multirow[t]{3}{*}{$P C-2$} & AhR-TEQ & 0.834 & 10.08 & 22.35 \\
\hline & $\mathrm{Fe}$ & 0.758 & & \\
\hline & AR-AEQ & 0.658 & & \\
\hline \multirow[t]{5}{*}{ PC-3 } & I & 0.763 & 10.05 & 32.40 \\
\hline & $\mathrm{Zn}$ & 0.706 & & \\
\hline & T3-ThEQ & 0.589 & & \\
\hline & $\mathrm{Cr}$ & 0.427 & & \\
\hline & $\mathrm{Pb}$ & 0.326 & & \\
\hline \multirow[t]{4}{*}{ PC-4 } & $\mathrm{Mn}$ & 0.777 & 8.43 & 40.83 \\
\hline & E2 & 0.763 & & \\
\hline & ER-EEQ & 0.347 & & \\
\hline & $\mathrm{Cr}$ & 0.316 & & \\
\hline \multirow[t]{4}{*}{$P C-5$} & $\mathrm{~Pb}$ & 0.778 & 8.34 & 49.17 \\
\hline & $\mathrm{Cd}$ & 0.729 & & \\
\hline & $\mathrm{Cu}$ & 0.424 & & \\
\hline & $\mathrm{Cr}$ & 0.327 & & \\
\hline \multirow[t]{3}{*}{ PC-6 } & Se & 0.746 & 7.76 & 56.93 \\
\hline & As & 0.691 & & \\
\hline & $\mathrm{Cu}$ & 0.480 & & \\
\hline \multirow[t]{2}{*}{ PC-7 } & testosterone & 0.818 & 7.71 & 64.63 \\
\hline & ER-EEQ & 0.622 & & \\
\hline
\end{tabular}

$P C$ principal component

${ }^{a}$ Factor loadings are the correlation coefficients between the original variables (levels of chemicals and receptor transactivities) and the extracted components. Variable levels are sorted by the size of the loading coefficients. Variable levels with factor loading below $|0.30|$ are not listed

abilities among children with higher prenatal PFOA exposure [89], and increasing maternal blood PFOA concentrations were reported to be associated with fewer autistic behaviors [12]. Other studies did not find positive correlation between maternal PFAS exposure and attention-deficit hyperactivity disorder (ADHD) or ASD [90, 91]. Our previous study showed that PFAS, such as PFOS and PFOA, elicited estrogenic and anti-androgenic potential in vitro and ex vivo [23, 92]. In support, in the present study, we found PFAS levels positively correlated to the combined xenoestrogenic effect (EDC-EEQ) while inversely correlated to the combined xenoandrogenic effect (EDC-AEQ). The fetus seems to be uniquely sensitive to the anti-androgenic effect of EDCs. Given their anti-androgenic properties, one could hypothesize that PFAS exposure might reduce the risk of autism. This observation might partly explain the inverse association between PFAS level in AF and ASD risk observed in the present study. Moreover, in vitro studies report that PFOA and PFOS are partial agonists of the human peroxisome proliferator-activated receptor- $\gamma$ (PPAR- $\gamma)$, and PPAR- $\gamma$ activation may be neuroprotective [93].

In the present AF study, we observed the ratio of AR-AEQ/ER-EEQ was non-significantly positively associated with ASD risk. AR-AEQ/ER-EEQ represents the proportion of total combined androgenic effect contributed by androgen and EDCs to the total combined estrogenic effect contributed by endogenous estrogen and EDCs. Hence, it is worthy to further study whether EDCs play a role in the development of ASD together with endogenous hormones. 



Fig. 2 (See legend on next page.) 
(See figure on previous page.)

Fig. 2 Plots of rotated factor loading of the three largest principal components (PCS) identified by principal component analysis (PCA). The percentage of variation (\%) explained by each PC variable is presented in parenthesis in the axis label. a Plots PC-1 loading against PC-2. b Plots PC-1 against PC-3. c Plots PC-2 against PC-3. Red dots are main component of PC-1, blue dots are main components of PC-2, and orange dots are main components of $\mathrm{PC}-3$. White dots indicate lower factor loading $(<|0.3|)$. For the detail on factor loading scores, see Table 9

Existing studies of autism suggest that prenatal metal exposure may be related to autism [94]. Exposure to $\mathrm{Pb}$ during neurodevelopment has significant effects on neurobehavioral and intellectual performance, also resulting in attention, hyperactivity, and learning disorders [17, $95,96]$. Lead poisoning has been suggested as a possible risk factor for autism, as $\mathrm{Pb}$ blood levels of autistic children have been reported to be significantly higher than those of healthy children [97]. Previous studies have shown that perinatal exposure to $\mathrm{Mn}, \mathrm{Pb}$, and $\mathrm{Cd}$ from air pollution increased ASD risk [42]. In the present study, we observed that $\mathrm{As}$ and $\mathrm{Pb}$ levels in $\mathrm{AF}$ tend to be positively associated with ASD risk, suggesting the possible role of prenatal exposure to toxic metals in the ASD development. However, given that these metals were detectable in less than $34 \%$ of the AF samples, more studies are needed to explore the role of prenatal heavy metal exposure on the risk of ASD.

There are several strengths in this study. First, the measurements of chemicals and receptor transactivities were based on the AF samples collected in pregnancy from routine amniocentesis prior to the assessment of the outcome in the offspring. Study participants were selected from a well-defined nation-wide pregnancy cohort and case-control matched by gender, year of birth, and maternal age. The outcome measures were clinical diagnoses using standardized diagnostic criteria (ICD classification), and diagnoses of autism in the psychiatric registry have been shown to have high validity [50]. Secondly, many exposure parameters were determined simultaneously in the single AF sample. This minimizes bias from differential misclassification. Thirdly, for the very first time, the combined mixture effect of EDCs was determined in AF. Moreover, the measurements of receptor transactivities consider the combined effect of EDC mixtures and endogenous hormones in AF. However, multiple testing issue should be addressed. We used the Benjamini-Hochberg method to control false discovery rate (FDR) and found that the significant association with the most individual exposure biomarker variables did not persist and thus cannot exclude a chance finding.

People are exposed to the mixture of different substances simultaneously, and therefore, it is important to assess the effect of actual combined effect of a mixture and principal component analysis (PCA) might provide the possibility to address this issue. The PCA extracts effective information from multidimensional data and is a powerful method to reduce the large number of highly correlated variables, so that results in fewer variables to be examined statistically. PCA reduced the false positive results by reducing the number of variables. Furthermore, PCA allows for the determination of which variables have common patterns of variances. PCA has been widely used for epidemiological studies [69]. To this aim, we further used PCA to extract the integrated principal component and analyzed the association of identified components and ASD risk. We observed a significantly negative association of ASD risk and the first principle component (PC-1), dominated by PFAS congeners and including $\mathrm{Cu}, \mathrm{Fe}$, and ER-EEQ, and the association persisted after corrected by FDR. Although it is difficult to interpret this observation clinically, this observation might suggest a role of combined effect of

Table 10 Odds ratio and 95\% confidence intervals for ASD according to PCA components

\begin{tabular}{|c|c|c|c|c|c|c|c|}
\hline & \multicolumn{2}{|l|}{ Crude } & \multirow[b]{2}{*}{$p$} & \multicolumn{2}{|l|}{ Adjusted $^{a}$} & \multirow[b]{2}{*}{$p$} & \multirow[b]{2}{*}{ FDR ( $\left.q_{\text {values }}\right)$} \\
\hline & $n$ (cases/controls) & OR $(95 \% \mathrm{Cl})$ & & $n$ (cases/controls) & OR $(95 \% \mathrm{Cl})$ & & \\
\hline PC-1 & $29 / 44$ & $0.236(0.092,0.607)$ & 0.003 & $29 / 44$ & $0.100(0.016,0.630)$ & 0.014 & 0.098 \\
\hline$P C-2$ & $29 / 44$ & $0.793(0.449,1.398)$ & 0.422 & $29 / 44$ & $0.943(0.456,1.948)$ & 0.873 & 0.961 \\
\hline$P C-3$ & $29 / 44$ & $1.180(0.733,1.897)$ & 0.496 & $29 / 44$ & $1.059(0.538,2.082)$ & 0.868 & 0.868 \\
\hline PC-4 & $29 / 44$ & $1.167(0.724,1.880)$ & 0.526 & $29 / 44$ & $1.027(0.363,2.903)$ & 0.961 & 0.961 \\
\hline$P C-5$ & $29 / 44$ & $1.064(0.668,1.695)$ & 0.793 & $29 / 44$ & $1.431(0.810,2.531)$ & 0.218 & 0.763 \\
\hline PC-6 & $29 / 44$ & $1.061(0.664,1.697)$ & 0.804 & $29 / 44$ & $1.258(0.661,2.393)$ & 0.485 & 0.849 \\
\hline PC-7 & $29 / 44$ & $1.25(0.773,2.025)$ & 0.363 & $29 / 44$ & $1.354(0.662,2.767)$ & 0.407 & 0.849 \\
\hline
\end{tabular}

$P C$ principal component, $F D R$ ( $q_{\text {value }}$ ) false discovery rate. For component of PC-1 PC-7, see Table 9. Italicized values indicate statistically significant $(p \leq 0.05$ and FDR $q_{\text {value }}<0.25$ )

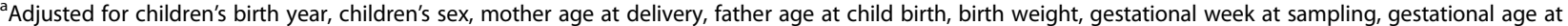
birth, Apgar score, parity, and congenital malformation 
PFAS, $\mathrm{Cu}, \mathrm{Fe}$, and estrogenic EDCs on the risk of ASD and further studies are needed to explore the combined effect of substances which the fetus are exposed to simultaneously. It has been shown that the different PFAS congeners are highly correlated. Our previous studies have shown PFAS elicited the estrogenic effect and anti-androgenic effect [23, 92]. This was further confirmed by the result regarding the correlation of PFAS and receptor transactivities in the present study. Therefore, it is reasonable that PFAS congeners and ER-EEQ were identified in the same component. It is not clear why nutrients $\mathrm{Cu}$ and $\mathrm{Fe}$ were gathered together with PFAS and ER-EEQ. More studies are needed to explore whether it is because of similar exposure pathway.

In the present study, we included congenital malformation cases in the data set. Given the genetic factors that contributed ASD, we performed the sensitive analysis by further adjustment of congenital malformation and excluding cases with congenital malformation. The results did not change significantly because congenital malformation of cases and non-cases did not have significantly different levels in the exposure variables of interest.

This study has also some limitations. Firstly, the sample size in the present study was small due to toxic effect of rubber tube plugs used in connection with some of the cell culture analyses, and volume restriction for the parameters measured in each AF samples. The statistical power is thus expected to be low, and this might explain the lack of statistical significance. Because this study is the first study to explore the association of AF levels of PFAS and the combined EDC and endogenous hormone ex vivo receptor transactivities and ASD risk, it is hard to perform priori power calculation at the design stage. Nevertheless, we calculated the statistical power based on the average levels of exposure variables and the power ranged from 5.0 to $68.6 \%$ for individual exposure biomarkers. However, by using data reduction technique principal component analysis (PCA), the power is high for the first two identified principal components (PC-1 98.5\%, PC-2 99.0\%, respectively). Secondly, studies have reported that PFAS reduced fecundity in humans [98, 99]. Therefore, it is possible that PFAS exposure at a level that reduces fetal survival, especially in high-risk fetuses susceptible to neurological disorders such as ASD, could appear to have a null or even protective effect on adverse neurobehavioral outcomes in children in observational studies affected by selection bias, since only live born children can be followed-up and examined. All psychiatric and somatic diagnoses were retrieved from nation-wide registers (DPCR and DNHR), and no information on autistic clinical symptomatology was available to validate the diagnoses. However, other studies have shown that within the DPCR the validity ratio for childhood autism cases is $94.0 \%$ for 1990-1999 [50]. Thirdly, the measurements of chemicals and biomarkers of effects such as the combined (endogenous hormones and EDCs) induced receptor transactivities were done from a historic collection of the AF samples stored over several years at $-20^{\circ} \mathrm{C}$. However, for the cohort analyzed in this study (born between 1995 and 1999), storage time-dependent changes are unlikely to be a major issue [14]. The prevalence estimate of autism within this amniocentesis cohort $(0.72 \%)$ is consistent with prevalence estimates of autism in the Danish population during the same time period [4]. Thus, although these results are derived from a selected sample, they may be representative of what would be expected in the general population. In the future, it is necessary to sample more representatives from the general population and collect more data regarding risk factors for fetal survival to further explore the integrated effect of EDCs on the development of autism. Finally, AF is an aqueous solution with suspended desquamated fetal epithelial cells. As gestation progresses, other organic materials including fetal feces and urine are also present. AF contains approximately equal parts of organics (proteins, carbohydrates, fats, enzymes, hormones, pigments) and inorganics. In human serum, some PFAS binds to circulating proteins (serum albumin) [100]. It is possible that some PFAS congeners were removed from the AF sample during its initial processing for clinical care purposes when the fluid was centrifuged and the precipitated cells retained for genetic testing [76]. Thus, the concentrations of PFAS in the AF samples might be underestimated and blur their effect on ASD.

\section{Conclusions and perspectives}

The present study showed that environmental endocrine disrupting chemicals (EDCs), such as PFAS, some metals, and their biological activities can be detected in amniotic fluid, indicating that EDCs can cross the placenta and increase the potential fetal exposure to these environment contaminants. EDCs might modify ASD risk by influencing the hormone receptor function. The inverse association between PFAS levels and ASD risk might relate to a weak estrogenic activities and anti-androgenic activities of single PFAS congener observed in vitro. The observed tendency of positive association between the ratio of combined androgenic effect to the combined estrogenic effect and ASD risk needs further studies to explore the role of combined effect of EDCs together with endogenous hormones in the development of ASD. However, individual variability in genetic susceptibility can influence responses to environmental toxicants and contribute to increase disease vulnerabilities. Several studies have reported that some individuals with ASD express polymorphisms in genes involved in the detoxification of environmental pollutants and these genes have been termed "environmental response genes." More 
than 100 environmental response genes may contribute to ASD risk [101, 102]. Therefore, it is necessary to study the role of gene polymorphisms and gene environment interaction in the development of ASD.

\section{Additional files}

Additional file 1: The percentage of PFAS in the amniotic fluid samples which were above the detection limit. (DOCX $26 \mathrm{~kb}$ )

Additional file 2: The percentage of elements in the amniotic fluid samples which were above the detection limit. (DOCX $18 \mathrm{~kb}$ )

Additional file 3: Adjusted odds ratio and $95 \%$ confidence intervals for ASD according to chemicals in amniotic fluid stratified by gender. (DOCX $20 \mathrm{~kb}$ )

Additional file 4: Adjusted odds ratio and 95\% confidence intervals for ASD according to chemicals, hormone level and receptor transactivity induced by amniotic fluid after removing congenital malformation. (DOCX $23 \mathrm{~kb}$ )

Additional file 5: Adjusted odds ratio and 95\% confidence intervals for ASD according to hormone level and receptor transactivity induced by amniotic fluid stratified by gender. (DOCX $19 \mathrm{~kb}$ )

Additional file 6: Descriptive statistics for the exposure biomarkers with detection frequency $>10 \%$ in amniotic fluid and used in the principal component analysis. (DOCX $17 \mathrm{~kb}$ )

Additional file 7: Level of PCA scores. (DOCX $18 \mathrm{~kb}$ )

Additional file 8: Adjusted odds ratio and $95 \%$ confidence intervals for ASD according to PCA component stratified by gender. (DOCX $17 \mathrm{~kb}$ )

Additional file 9: Adjusted odds ratio and 95\% confidence intervals for ASD according to PCA component after removing congenital malformation. (DOCX $17 \mathrm{~kb})$

\section{Abbreviations}

ADHD: Attention-deficit hyperactivity disorder; AEQ: Androgen equivalent; AF: Amniotic fluid; AhR: Aryl hydrocarbon receptor; AhR-tact: Aryl hydrocarbon receptor transactivity; AR: Androgen receptor; ARtact: Androgen receptor transactivity; ASD: Autism spectrum disorder; CDFCS: Charcoal-dextran-treated fetal calf serum; DHT: Dihydrotestosterone; DMEM: Dulbecco's modified Eagle medium; DNHR: Danish National Hospital Register; DPCR: Danish Psychiatric Central Register; E2: 17ß-Estradiol; EDC$A E Q$ : EDC-induced androgenic effect; EDC-EEQ: EDC-induced estrogenic effect; EDCs: Endocrine disrupting compounds; EEQ: Estradiol equivalent; ER: Estrogen receptor; ER-tact: Estrogen receptor transactivity; FDR: False discovery rate; HBC: Historic Birth Cohort; ICD: International Classification of Diseases; OCP: Organchlorine pesticide; OR: Odds ratio;

PBDE: Polybrominated diphenyl ether; PC: Principal component; PCA: Principal component analysis; PCB: Polychlorinated biphenyl; PE: Proliferation effect; PFAS: Perfluoroalkyl substances; PFBS: Perfluorobutane sulfonate; PFCA: Perfluorocarboxylated acids; PFDA: Perfluorodecanoic acid; PFDoA: Perfluorododecanoic acid; PFDS: Perfluorodecane sulfonate; PFHpA: Perfloroheptanoate; PFHpS: Perfluoroheptane sulfonate; PFHXA: Perfluorohexanoic acid; PFHxS: Perfluorohexane sulfonate: PFNA: Perfluorononanoic acid; PFOA: Perfluorooctanoic acid; PFOS: Perfluorooctane sulfonate; PFOSA: Perfluorooctane sulfonamide; PFPeA: Perfluoro-n-pentanoic acid; PFSA: Perfluorosulfonated acids; PFUnA: Perfluoroundecanoic acid; POP: Persistent organic pollutants; POSF: Perfluorooctanesulfonyl-fluoride; PPAR: Proliferator-activated receptor; T3: Triiodothyronine; TCDD: 2, 3, 7, 8-Tetrachlorodibenzo-p-dioxin; TEQ: TCDD equivalent; TH: Thyroid hormone; ThEQ: Thyroid equivalent; TH-PE: Thyroid hormone-related proliferative effect

\section{Acknowledgements}

We thank members of the Centre for Arctic Health \& Molecular Epidemiology research group, especially Tanja Krüger for technical and scientific support regarding the AR transactivation assay and Dorte Olsson for technical assistance. We thank Rossana Bossi and Gert Asmund for the measurement of PFAS and metals.

\section{Funding}

This study was funded by Aarhus University, Health Faculty, Aarhus, Denmark, and Statens Serum Institute, Copenhagen, Denmark, and Danish Research and Innovation Council (Project ID: 271-07-0385). The Historic Birth Cohort (HBC) is part of the Danish National Biobank supported by the Novo Nordisk Foundation.

\section{Availability of data and materials}

The data used in the study are available from the corresponding author upon reasonable request.

\section{Authors' contributions}

ECB-J was the principle investigator mainly responsible for the study design. LK performed ER transactivity and AR transactivity, MG performed TH-like activity, and ML performed AhR transactivity assays and data evaluation. ML collected the data and performed the statistical analysis. ML wrote the first draft, and ECB-J, MG, and MW contributed the final manuscript. BNP provided AF sample. MWA coordinated the population data. Grant 271-07-0385 was to ELM who also had a coordinating role on the project. All authors participated in commenting on the draft and have read and approved the final manuscript.

\section{Ethics approval and consent to participate}

The study was approved by the Steering Committee for Scientific Use of the Newborn Screening Biobank and the Danish Data Protection Agency (Record No. 2009-41-3173) as well as the Central Denmark Region Ethics Committee on Health Research (Record No. M-20090066). Since all data were obtained retrospectively in an anonymized manner, there was no need to obtain consent from any of the participants.

\section{Consent for publication \\ Not applicable}

\section{Competing interests}

The authors declare that they have no competing interests.

\section{Publisher's Note}

Springer Nature remains neutral with regard to jurisdictional claims in published maps and institutional affiliations.

\section{Author details}

${ }^{1}$ Centre for Arctic Health \& Molecular Epidemiology, Department of Public Health, Aarhus University, Aarhus, Denmark. 'Section of Neonatal Genetic, Danish Centre for Neonatal Screening, Statens Serum Institute, Copenhagen, Denmark. ${ }^{3}$ Section of Environmental Health, Department of Public Health, University of Copenhagen, Copenhagen, Denmark. ${ }^{4}$ Department of Child and Adolescent Psychiatry Hofheim, Vitos Psychiatric Hospital Riedstadt, Riedstadt, Germany. ${ }^{5}$ Greenland Center for Health Research, Greenland University, Nuuk, Greenland.

Received: 18 October 2017 Accepted: 7 December 2018

Published online: 09 January 2019

\section{References}

1. APA. Autism spectrum disorder, 299.00 (F84.0). In: American Psychiatric Association diagnostic and statistical manual of mental disorders. 5th ed. Arlington: American Psychiatric Publishing; 2013.

2. Baxter AJ, Brugha TS, Erskine HE, Scheurer RW, Vos T, Scott JG. The epidemiology and global burden of autism spectrum disorders. Psychol Med. 2015;45:601-13.

3. Newschaffer CJ, Croen LA, Daniels J, Giarelli E, Grether JK, Levy SE, Mandell DS, Miller LA, Pinto-Martin J, Reaven J, et al. The epidemiology of autism spectrum disorders. Annu Rev Public Health. 2007;28:235-58.

4. Parner ET, Schendel DE, Thorsen P. Autism prevalence trends over time in Denmark: changes in prevalence and age at diagnosis. Arch Pediatr Adolesc Med. 2008;162:1150-6.

5. Risch N, Spiker D, Lotspeich L, Nouri N, Hinds D, Hallmayer J, Kalaydjieva L, McCague P, Dimiceli S, Pitts T, et al. A genomic screen of autism: evidence for a multilocus etiology. Am J Hum Genet. 1999;65:493-507. 
6. Park HR, Lee JM, Moon HE, Lee DS, Kim BN, Kim J, Kim DG, Paek SH. A short review on the current understanding of autism spectrum disorders. Exp Neurobiol. 2016;25(1):13.

7. Schaefer GB, Mendelsohn NJ, Professional P, Guidelines C. Clinical genetics evaluation in identifying the etiology of autism spectrum disorders: 2013 guideline revisions. Genet Med. 2013;15:399-407.

8. Glasson EJ, Bower C, Petterson B, de Klerk N, Chaney G, Hallmayer JF. Perinatal factors and the development of autism: a population study. Arch Gen Psychiatry. 2004;61:618-27.

9. Roberts EM, English PB, Grether JK, Windham GC, Somberg L, Wolff C Maternal residence near agricultural pesticide applications and autism spectrum disorders among children in the California Central Valley. Environ Health Perspect. 2007;115:1482-9.

10. Volk HE, Hertz-Picciotto I, Delwiche L, Lurmann F, McConnell R. Residential proximity to freeways and autism in the CHARGE study. Environ Health Perspect. 2011;119:873-7.

11. Windham GC, Zhang L, Gunier R, Croen LA, Grether JK. Autism spectrum disorders in relation to distribution of hazardous air pollutants in the San Francisco bay area. Environ Health Perspect. 2006;114:1438-44.

12. Braun JM, Kalkbrenner AE, Just AC, Yolton K, Calafat AM, Sjodin A, Hauser R, Webster GM, Chen A, Lanphear BP. Gestational exposure to endocrinedisrupting chemicals and reciprocal social, repetitive, and stereotypic behaviors in 4- and 5-year-old children: the HOME study. Environ Health Perspect. 2014;122:513-20.

13. Knickmeyer R, Baron-Cohen S, Fane BA, Wheelwright S, Mathews GA, Conway GS, Brook CG, Hines M. Androgens and autistic traits: a study of individuals with congenital adrenal hyperplasia. Horm Behav. 2006;50:148-53.

14. Baron-Cohen S, Auyeung B, Norgaard-Pedersen B, Hougaard DM, Abdallah MW, Melgaard L, Cohen AS, Chakrabarti B, Ruta L, Lombardo MV. Elevated fetal steroidogenic activity in autism. Mol Psychiatry. 2015;20:369-76.

15. Hallmayer J, Cleveland S, Torres A, Phillips J, Cohen B, Torigoe T, Miller J, Fedele A, Collins J, Smith K, et al. Genetic heritability and shared environmental factors among twin pairs with autism. Arch Gen Psychiatry. 2011;68:1095-102.

16. Rossignol DA, Frye RE. A review of research trends in physiological abnormalities in autism spectrum disorders: immune dysregulation, inflammation, oxidative stress, mitochondrial dysfunction and environmental toxicant exposures. Mol Psychiatry. 2012;17:389-401.

17. Costa LG, Aschner M, Vitalone A, Syversen T, Soldin OP. Developmental neuropathology of environmental agents. Annu Rev Pharmacol Toxicol. 2004;44:87-110

18. Ek CJ, Dziegielewska KM, Habgood MD, Saunders NR. Barriers in the developing brain and Neurotoxicology. Neurotoxicology. 2012;33:586-604.

19. Bonefeld-Jorgensen EC. Biomonitoring in Greenland: human biomarkers of exposure and effects - a short review. Rural Remote Health. 2010;10:1362.

20. Bonefeld-Jorgensen EC, Grunfeld HT, Gjermandsen IM. Effect of pesticides on estrogen receptor transactivation in vitro: a comparison of stable transfected MVLN and transient transfected MCF-7 cells. Mol Cell Endocrinol. 2005;244:20-30.

21. Ghisari M, Bonefeld-Jorgensen EC. Impact of environmental chemicals on the thyroid hormone function in pituitary rat GH3 cells. Mol Cell Endocrinol. 2005;244:31-41.

22. Long M, Laier P, Vinggaard AM, Andersen HR, Lynggaard J, BonefeldJorgensen EC. Effects of currently used pesticides in the AhR-CALUX assay: comparison between the human TV101L and the rat H4IIE cell line. Toxicology. 2003;194:77-93.

23. Kjeldsen LS, Bonefeld-Jorgensen EC. Perfluorinated compounds affect the function of sex hormone receptors. Environ Sci Pollut Res Int. 2013;20:8031-44.

24. Long $\mathrm{M}$, Ghisari $\mathrm{M}$, Bonefeld-Jorgensen EC. Effects of perfluoroalkyl acids on the function of the thyroid hormone and the aryl hydrocarbon receptor Environ Sci Pollut Res Int. 2013;20:8045-56.

25. Bonefeld-Jorgensen EC, Long M, Hofmeister MV, Vinggaard AM. Endocrinedisrupting potential of bisphenol A, bisphenol A dimethacrylate, 4-nnonylphenol, and 4-n-octylphenol in vitro: new data and a brief review. Environ Health Perspect. 2007;115(Suppl 1):69-76.

26. Ghisari M, Bonefeld-Jorgensen EC. Effects of plasticizers and their mixtures on estrogen receptor and thyroid hormone functions. Toxicol Lett. 2009; 189:67-77.

27. Kruger $\mathrm{T}$, Long $\mathrm{M}$, Bonefeld-Jorgensen EC. Plastic components affect the activation of the aryl hydrocarbon and the androgen receptor. Toxicology 2008;246:112-23.
28. Braun JM. Endocrine disrupting compounds, gonadal hormones, and autism. Dev Med Child Neurol. 2012;54:1068.

29. Landrigan PJ, Lambertini L, Birnbaum LS. A research strategy to discover the environmental causes of autism and neurodevelopmental disabilities. Environ Health Perspect. 2012;120:a258-60.

30. Fuentes S, Vicens P, Colomina MT, Domingo JL. Behavioral effects in adult mice exposed to perfluorooctane sulfonate (PFOS). Toxicology. 2007;242:123-9.

31. Johansson N, Eriksson P, Viberg H. Neonatal exposure to PFOS and PFOA in mice results in changes in proteins which are important for neuronal growth and synaptogenesis in the developing brain. Toxicol Sci. 2009;108:412-8.

32. Kim SM, Han DH, Lyoo HS, Min KJ, Kim KH, Renshaw P. Exposure to environmental toxins in mothers of children with autism spectrum disorder. Psychiatry Investig. 2010;7:122-7.

33. Eskenazi B, Marks AR, Bradman A, Harley K, Barr DB, Johnson C, Morga N, Jewell NP. Organophosphate pesticide exposure and neurodevelopment in young Mexican-American children. Environ Health Perspect. 2007;115:792-8.

34. Miodovnik A, Engel SM, Zhu C, Ye X, Soorya LV, Silva MJ, Calafat AM, Wolff MS. Endocrine disruptors and childhood social impairment. Neurotoxicology. 2011;32:261-7.

35. McCanlies EC, Fekedulegn D, Mnatsakanova A, Burchfiel CM, Sanderson WT, Charles LE, Hertz-Picciotto I. Parental occupational exposures and autism spectrum disorder. J Autism Dev Disord. 2012;42:2323-34.

36. Beard J. Iron deficiency alters brain development and functioning. J Nutr. 2003;133:1468S-72S

37. Bourre JM. Effects of nutrients (in food) on the structure and function of the nervous system: update on dietary requirements for brain. Part 1: micronutrients. J Nutr Health Aging. 2006;10:377-85.

38. Grandjean P, Landrigan PJ. Developmental neurotoxicity of industrial chemicals. Lancet. 2006;368:2167-78.

39. Kodama H, Fujisawa C, Bhadhprasit W. Pathology, clinical features and treatments of congenital copper metabolic disorders--focus on neurologic aspects. Brain and Development. 2011;33:243-51.

40. Walter T. Effect of iron-deficiency anemia on cognitive skills and neuromaturation in infancy and childhood. Food Nutr Bull. 2003;24:S104-10.

41. Winneke G. Developmental aspects of environmental neurotoxicology: lessons from lead and polychlorinated biphenyls. J Neurol Sci. 2011;308:9-15.

42. Roberts AL, Lyall K, Hart JE, Laden F, Just AC, Bobb JF, Koenen KC, Ascherio A, Weisskopf MG. Perinatal air pollutant exposures and autism spectrum disorder in the children of Nurses' Health Study II participants. Environ Health Perspect. 2013;121:978-84.

43. Bonefeld-Jorgensen EC, Ghisari M, Wielsoe M, Bjerregaard-Olesen C, Kjeldsen LS, Long M. Biomonitoring and hormone-disrupting effect biomarkers of persistent organic pollutants in vitro and ex vivo. Basic Clin Pharmacol Toxicol. 2014:115:118-28.

44. Long M, Bonefeld-Jorgensen EC. Dioxin-like activity in environmental and human samples from Greenland and Denmark. Chemosphere. 2012;89:919-28.

45. Beall MH, van den Wijngaard JP, van Gemert MJ, Ross MG. Regulation of amniotic fluid volume. Placenta. 2007;28:824-32.

46. Lyall K, Schmidt RJ, Hertz-Picciotto I. Maternal lifestyle and environmental risk factors for autism spectrum disorders. Int J Epidemiol. 2014;43:443-64.

47. Abdallah MW, Larsen N, Grove J, Norgaard-Pedersen B, Thorsen P, Mortensen EL, Hougaard DM. Amniotic fluid chemokines and autism spectrum disorders: an exploratory study utilizing a Danish Historic Birth Cohort. Brain Behav Immun. 2012;26:170-6.

48. Abdallah MW, Greaves-Lord K, Grove J, Norgaard-Pedersen B, Hougaard DM Mortensen EL. Psychiatric comorbidities in autism spectrum disorders: findings from a Danish Historic Birth Cohort. Eur Child Adolesc Psychiatry. 2011;20:599-601.

49. Norgaard-Pedersen B, Hougaard DM. Storage policies and use of the Danish Newborn Screening Biobank. J Inherit Metab Dis. 2007;30:530-6.

50. Lauritsen MB, Jorgensen M, Madsen KM, Lemcke S, Toft S, Grove J, Schendel $D E$, Thorsen P. Validity of childhood autism in the Danish Psychiatric Central Register: findings from a cohort sample born 1990-1999. J Autism Dev Disord. 2010;40:139-48.

51. Andersen TF, Madsen M, Jorgensen J, Mellemkjoer L, Olsen JH. The Danish National Hospital Register. A valuable source of data for modern health sciences. Dan Med Bull. 1999:46:263-8.

52. Knudsen LB, Olsen J. The Danish Medical Birth Registry. Dan Med Bull. 1998;45: 320-3.

53. Kugler KG, Hackl WO, Mueller LA, Fiegl H, Graber A, Pfeiffer RM. The impact of sample storage time on estimates of association in biomarker discovery studies. J Clin Bioinforma. 2011;1:9. 
54. Lauritsen MB, Pedersen CB, Mortensen PB. The incidence and prevalence of pervasive developmental disorders: a Danish population-based study. Psychol Med. 2004;34:1339-46.

55. Hansen KJ, Clemen LA, Ellefson ME, Johnson HO. Compound-specific, quantitative characterization of organic fluorochemicals in biological matrices. Environ Sci Technol. 2001;35:766-70.

56. Bonefeld-Jorgensen EC, Long M, Bossi R, Ayotte P, Asmund G, Kruger T, Ghisari M, Mulvad G, Kern P, Nzulumiki P, Dewailly E. Perfluorinated compounds are related to breast cancer risk in Greenlandic Inuit: a case control study. Environ Health. 2011;10:88.

57. Asmund G, Vorkamp K, Backus S, Comba M. An update on analytical methods, quality assurance and quality control used in the Greenland AMAP programme: 1999-2002. Sci Total Environ. 2004;331:233-45.

58. Lutchmaya S, Baron-Cohen S, Raggatt P, Knickmeyer R, Manning JT. 2nd to 4th digit ratios, fetal testosterone and estradiol. Early Hum Dev. 2004;77:238.

59. Elliott CT, Francis KS, Shortt HD, McCaughey WJ. Determination of the concentrations of the steroids estradiol, progesterone and testosterone in bovine sera: comparison of commercial dissociation enhanced lanthanide fluorescence immunoassay kits with conventional radio and enzyme immunoassays. Analyst. 1995;120:1827-30.

60. Long M, Deutch B, Bonefeld-Jorgensen EC. AhR transcriptional activity in serum of Inuits across Greenlandic districts. Environ Health. 2007:6:32.

61. Pang $S$, Levine LS, Chow D, Sagiani F, Saenger P, New MI. Dihydrotestosterone and its relationship to testosterone in infancy and childhood. J Clin Endocrinol Metab. 1979;48:821-6.

62. Wilson EM, French FS. Binding properties of androgen receptors. Evidence for identical receptors in rat testis, epididymis, and prostate. J Biol Chem. 1976;251:5620-9

63. Greenland S. Modeling and variable selection in epidemiologic analysis. Am J Public Health. 1989;79:340-9.

64. Jensen MS, Norgaard-Pedersen B, Toft G, Hougaard DM, Bonde JP, Cohen A Thulstrup AM, Ivell $\mathrm{R}$, Anand-Ivell R, Lindh $\mathrm{CH}$, Jonsson BA. Phthalates and perfluorooctanesulfonic acid in human amniotic fluid: temporal trends and timing of amniocentesis in pregnancy. Environ Health Perspect. 2012;120:897-903.

65. James WH. A potential explanation of some established major risk factors for autism. Dev Med Child Neurol. 2012;54:301-5.

66. Maimburg RD, Vaeth M. Perinatal risk factors and infantile autism. Acta Psychiatr Scand. 2006;114:257-64.

67. Benjamini $Y$, Hochberg Y. Controlling the false discovery rate: a practical and powerful approach to multiple testing. J Royal Stat Soc Ser B. 1995;57:289-300.

68. Glickman ME, Rao SR, Schultz MR. False discovery rate control is a recommended alternative to Bonferroni-type adjustments in health studies. J Clin Epidemiol. 2014;67:850-7.

69. Handbook of biological statistics: multiple comparisons. http://www. biostathandbook.com/multiplecomparisons.html. Accessed 24 July 2018.

70. Ferri SL, Abel T, Brodkin ES. Sex differences in autism spectrum disorder: a review. Curr Psychiatry Rep. 2018;20:9.

71. Timonen-Soivio L, Vanhala R, Malm H, Leivonen S, Jokiranta E, Hinkka-YliSalomaki S, Gissler M, Brown AS, Sourander A. The association between congenital anomalies and autism spectrum disorders in a Finnish national birth cohort. Dev Med Child Neurol. 2015;57:75-80.

72. Jolliffe IT, Cadima J. Principal component analysis: a review and recent developments. Philos Trans A Math Phys Eng Sci. 2016;374:20150202.

73. Los CA. The prejudices of least squares, principal components and common factors schemes. Computers Math Applic. 1989;17:1269-83.

74. Liberda EN, Tsuji L, Martin ID, Cote S, Ayotte P, Dewailly E, Nieboer E. Plasma concentrations of persistent organic pollutants in the Cree of northern Quebec, Canada: results from the multi-community environmentand-health study. Sci Total Environ. 2014;470-471:818-28.

75. Newby PK, Tucker KL. Empirically derived eating patterns using factor or cluster analysis: a review. Nutr Rev. 2004;62:177-203.

76. Stein CR, Wolff MS, Calafat AM, Kato K, Engel SM. Comparison of polyfluoroalkyl compound concentrations in maternal serum and amniotic fluid: a pilot study. Reprod Toxicol. 2012;34:312-6.

77. Land M, de Wit CA, Bignert A, Cousins IT, Herzke D, Johansson JH, Martin JW. What is the effect of phasing out long-chain per- and polyfluoroalkyl substances on the concentrations of perfluoroalkyl acids and their precursors in the environment? A systematic review. Environ Evid. 2018;7:4

78. Olsen GW, Mair DC, Reagen WK, Ellefson ME, Ehresman DJ, Butenhoff J Zobel LR. Preliminary evidence of a decline in perfluorooctanesulfonate
(PFOS) and perfluorooctanoate (PFOA) concentrations in American Red Cross blood donors. Chemosphere. 2007;68:105-11.

79. Bjerregaard-Olesen C, Bach CC, Long M, Ghisari M, Bossi R, Bech BH, Nohr EA, Henriksen TB, Olsen J, Bonefeld-Jorgensen EC. Time trends of perfluorinated alkyl acids in serum from Danish pregnant women 20082013. Environ Int. 2016;91:14-21.

80. Vestergren R, Cousins IT. Tracking the pathways of human exposure to perfluorocarboxylates. Environ Sci Technol. 2009;43:5565-75.

81. Lehmler HJ. Synthesis of environmentally relevant fluorinated surfactants--a review. Chemosphere. 2005;58:1471-96.

82. Slotkin TA, MacKillop EA, Melnick RL, Thayer KA, Seidler FJ. Developmental neurotoxicity of perfluorinated chemicals modeled in vitro. Environ Health Perspect. 2008;1 16:716-22.

83. Baron-Cohen S, Lombardo MV, Auyeung B, Ashwin E, Chakrabarti B, Knickmeyer $\mathrm{R}$. Why are autism spectrum conditions more prevalent in males? PLoS Biol. 2011;9:e1001081.

84. Auyeung B, Baron-Cohen S, Ashwin E, Knickmeyer R, Taylor K, Hackett G. Fetal testosterone and autistic traits. Br J Psychol. 2009;100:1-22.

85. Auyeung B, Ahluwalia J, Thomson L, Taylor K, Hackett G, O'Donnell KJ, Baron-Cohen S. Prenatal versus postnatal sex steroid hormone effects on autistic traits in children at 18 to 24 months of age. Mol Autism. 2012;3:17.

86. Sarachana T, Xu M, Wu RC, Hu WW. Sex hormones in autism: androgens and estrogens differentially and reciprocally regulate RORA, a novel candidate gene for autism. PLoS One. 2011;6:e17116.

87. Werling DM, Geschwind DH. Sex differences in autism spectrum disorders Curr Opin Neurol. 2013;26:146-53.

88. Power MC, Webster TF, Baccarelli AA, Weisskopf MG. Cross-sectional association between polyfluoroalkyl chemicals and cognitive limitation in the National Health and Nutrition Examination Survey. Neuroepidemiology. 2013;40:125-32

89. Stein CR, Savitz DA, Bellinger DC. Perfluorooctanoate and neuropsychological outcomes in children. Epidemiology. 2013;24:590-9.

90. Strom M, Hansen S, Olsen SF, Haug LS, Rantakokko P, Kiviranta H, Halldorsson TI. Persistent organic pollutants measured in maternal serum and offspring neurodevelopmental outcomes--a prospective study with long-term follow-up. Environ Int. 2014;68:41-8.

91. Liew Z, Ritz B, von Ehrenstein OS, Bech BH, Nohr EA, Fei C, Bossi R, Henriksen TB, Bonefeld-Jorgensen EC, Olsen J. Attention deficit/hyperactivity disorder and childhood autism in association with prenatal exposure to perfluoroalkyl substances: a nested case-control study in the Danish National Birth Cohort. Environ Health Perspect. 2015;123:367-73.

92. Bjerregaard-Olesen C, Ghisari M, Bonefeld-Jorgensen EC. Activation of the estrogen receptor by human serum extracts containing mixtures of perfluorinated alkyl acids from pregnant women. Environ Res. 2016;151:71-9.

93. Kapadia R, Yi JH, Vemuganti R. Mechanisms of anti-inflammatory and neuroprotective actions of PPAR-gamma agonists. Front Biosci. 2008;13:1813-26.

94. Kalkbrenner AE, Schmidt RJ, Penlesky AC. Environmental chemical exposures and autism spectrum disorders: a review of the epidemiological evidence. Curr Probl Pediatr Adolesc Health Care. 2014;44:277-318.

95. Mendola P, Selevan SG, Gutter S, Rice D. Environmental factors associated with a spectrum of neurodevelopmental deficits. Ment Retard Dev Disabil Res Rev. 2002;8:188-97.

96. Winneke G, Kramer U. Neurobehavioral aspects of lead neurotoxicity in children. Cent Eur J Public Health. 1997:5:65-9.

97. Zafeiriou DI, Ververi A, Vargiami E. Childhood autism and associated comorbidities. Brain and Development. 2007;29:257-72.

98. Fei C, McLaughlin JK, Lipworth L, Olsen J. Maternal levels of perfluorinated chemicals and subfecundity. Hum Reprod. 2009;24:1200-5.

99. Buck Louis GM, Sundaram R, Schisterman EF, Sweeney AM, Lynch CD, GoreLangton RE, Maisog J, Kim S, Chen Z, Barr DB. Persistent environmental pollutants and couple fecundity: the LIFE study. Environ Health Perspect. 2013;121:231-6

100. Luo Z, Shi X, Hu Q, Zhao B, Huang M. Structural evidence of perfluorooctane sulfonate transport by human serum albumin. Chem Res Toxicol. 2012;25:990-2.

101. Lawler CP, Croen LA, Grether JK, Van de Water J. Identifying environmental contributions to autism: provocative clues and false leads. Ment Retard Dev Disabil Res Rev. 2004;10:292-302.

102. Herbert MR, Russo JP, Yang S, Roohi J, Blaxill M, Kahler SG, Cremer L, Hatchwell E. Autism and environmental genomics. Neurotoxicology. 2006; 27:671-84. 